\title{
برنامج قائم على استراتيجية التعلم المعكوس لتنمية مهارة القراءة \\ باللغه الإنجليزية لاى طفل الروضة
}

اعداد

الباحثة / ريهام عبد الهادى عارف سعد الاجوى'

اشر افت

أ.د.هدى محمود الناشف

أستاذ تربية الطقل المتفرغ بقسم العلوم التربوية
أ.د · منى عحم على جاد

أستاذ تربية الطقل بقسم العلوم التربوية

أولا: مدخل لمشكلة البحث:

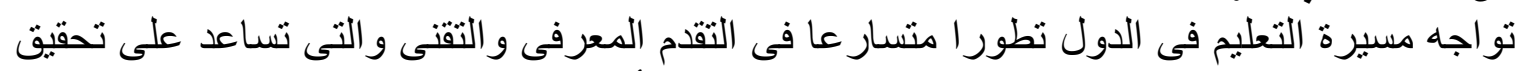

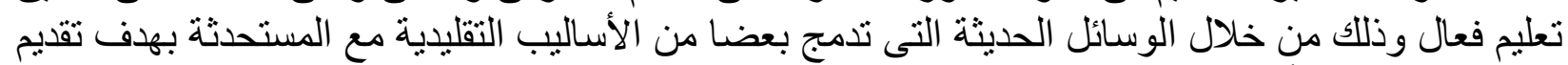

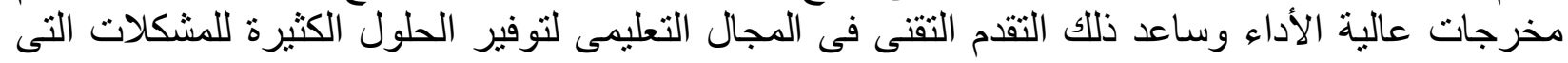

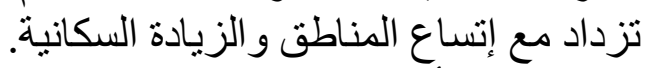

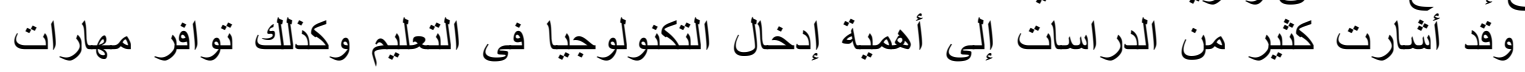

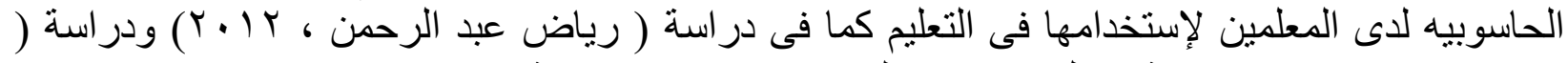

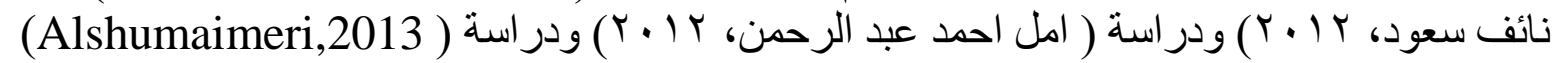

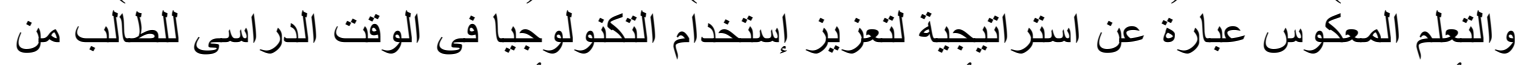

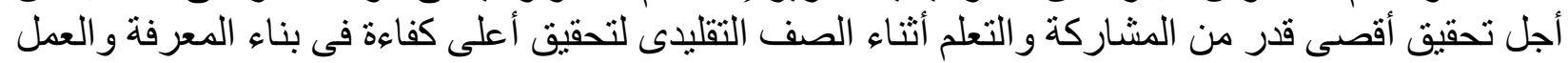

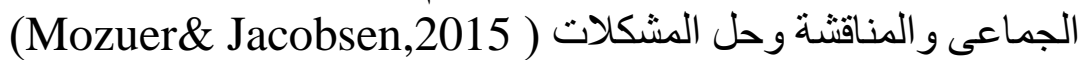

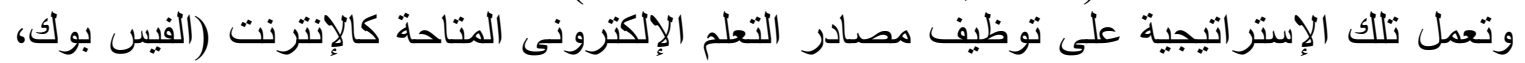

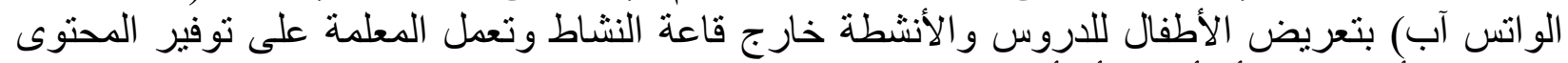

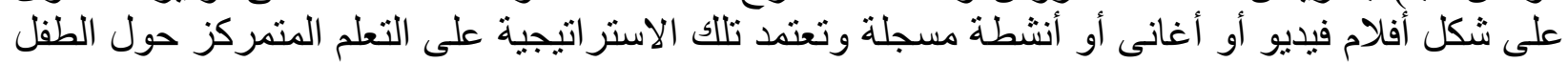

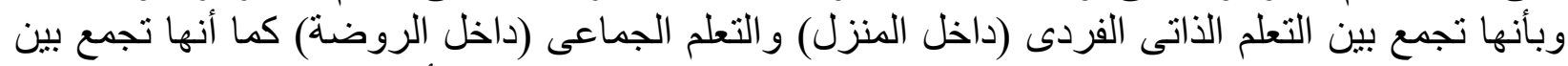

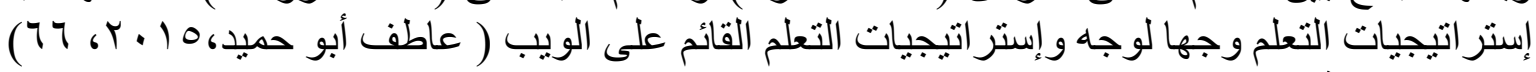

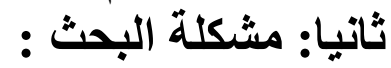

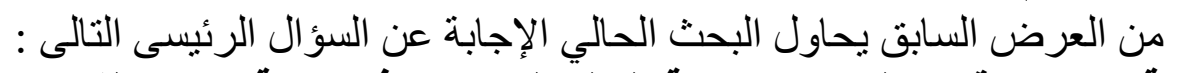

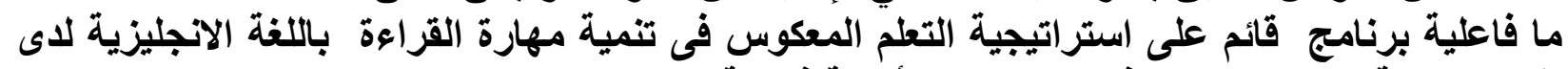

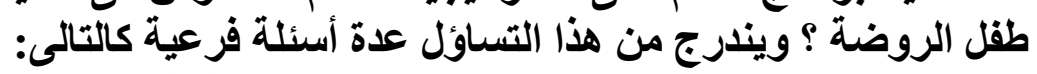

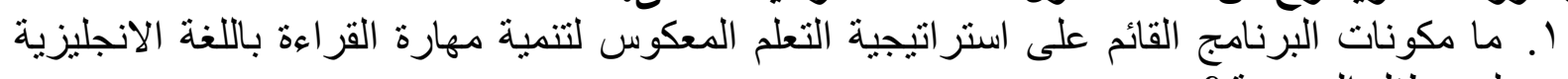

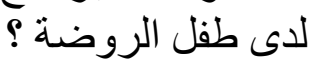

ץ. ما بيئة التعلم التى بعتمد عليها التعلم المعكوس الفعال داخل الروضة بوضعها الر اهن ؟ 
ب. ما الإستر اتيجيات التى يقوم عليها البرنامج المقترح القائم على استر اتيجية التعلم المعكوس في تنمية مهارة القر اعة لدى طفل الرجات الروضن

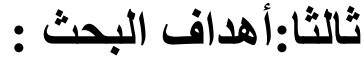

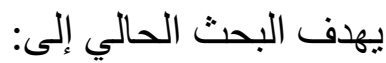

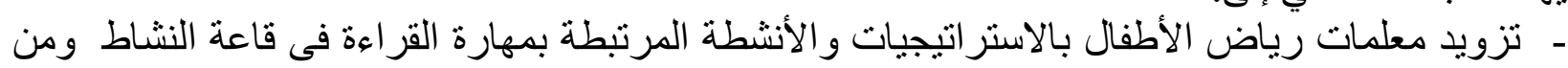
خلال وسائط الكترونية.

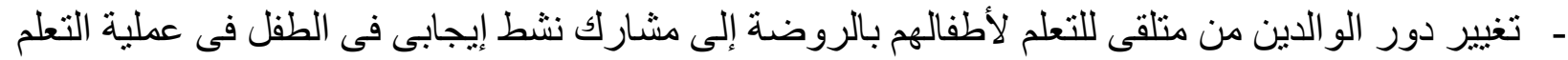

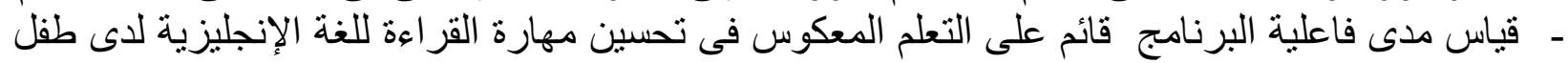
الروضة. - فاعلية تطبيق التعلم المعكوس فى تتمية مهارة الاستعداد للقر اءة لطفل الروضة من خلال وحدة

Home رابعا: أهمية البحث: أهم:

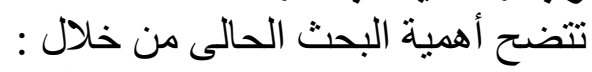

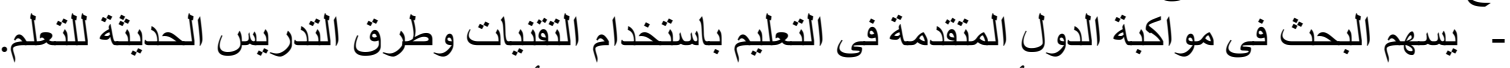

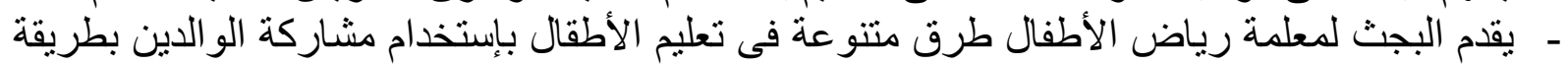

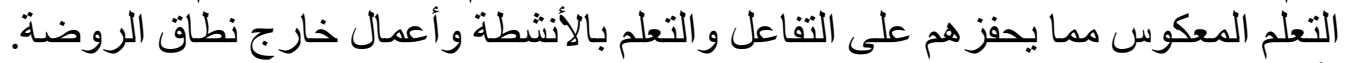

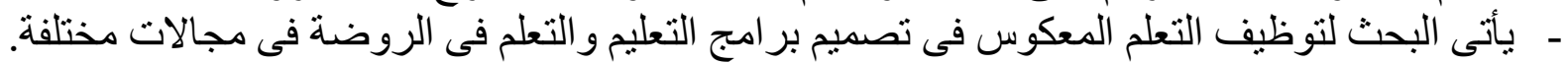

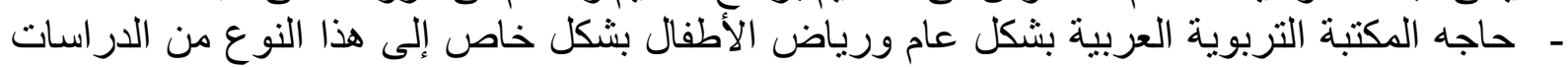

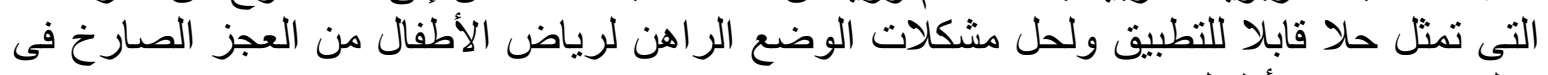
معلمات رياض الأطفال. خامسا: مصطلحات البحث:

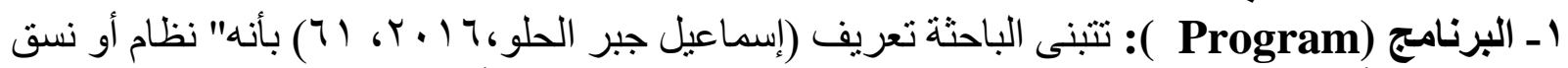

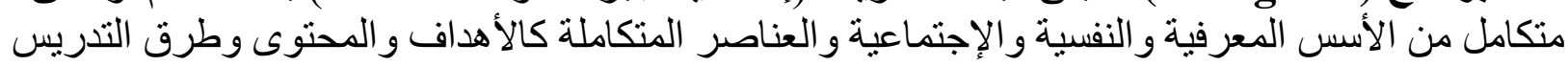

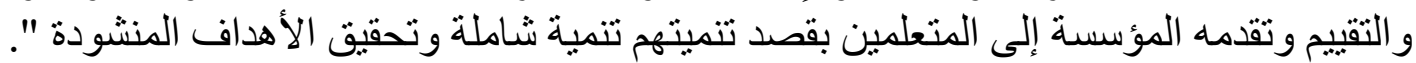

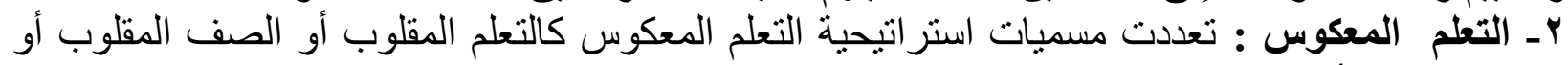

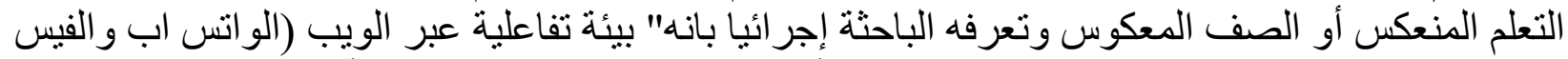

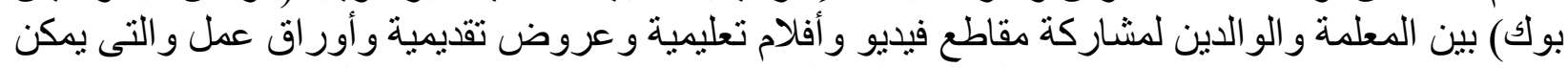

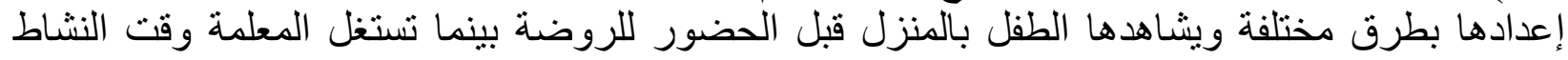

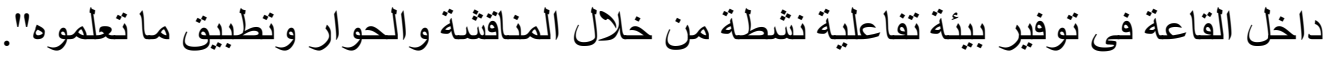

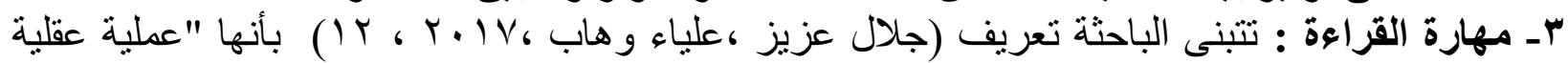

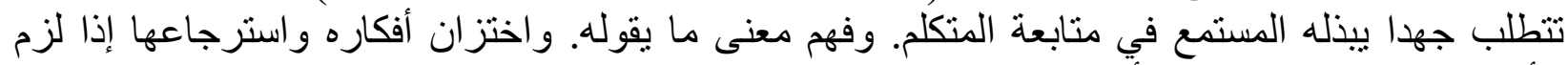

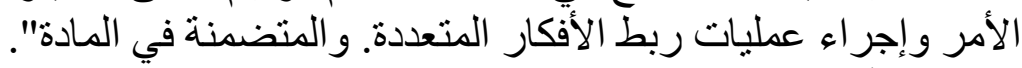

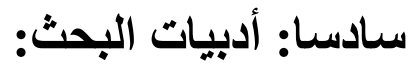

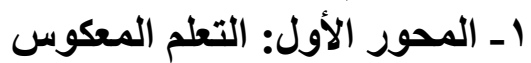

قد شهذ تعاون الأسرة والروضة المونة في الدول المتقدمة تطورا ملحوظا حيث أصبح جزءاء من العملية

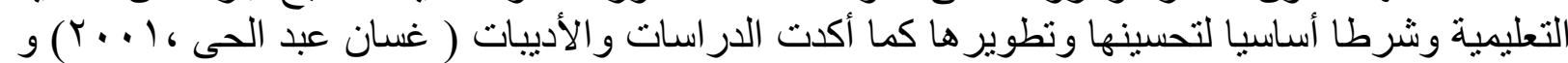

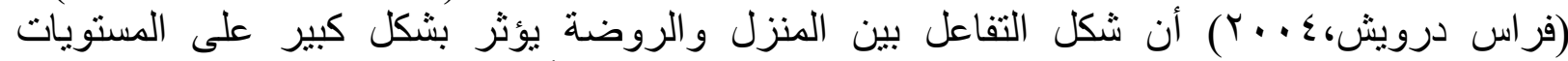

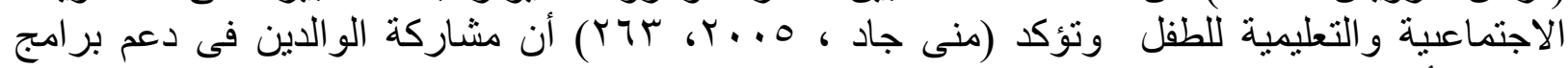

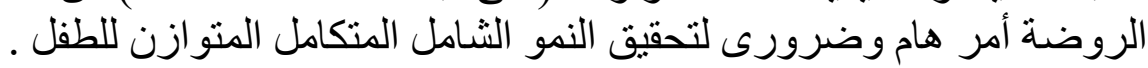

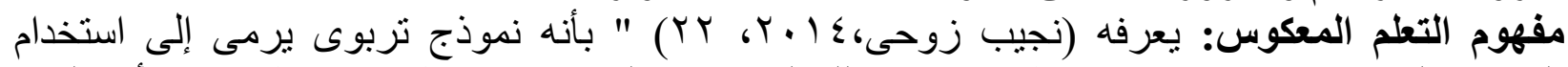

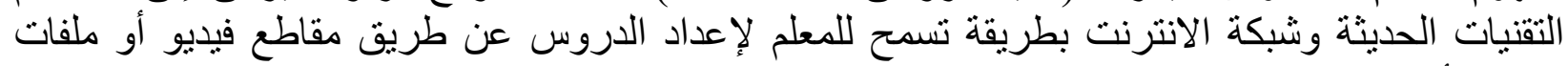

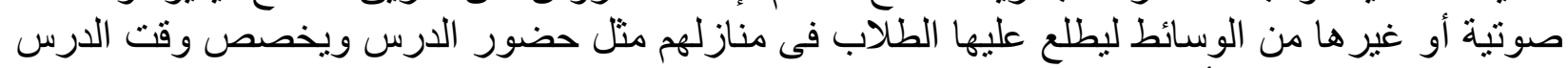
للمناقتشة و التدريبيات و الأنشطة التطبية التطبية 


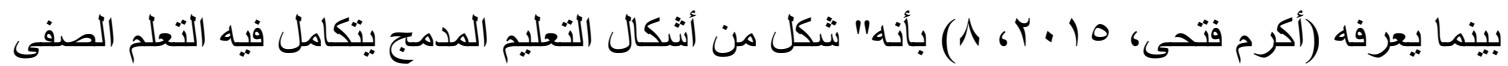

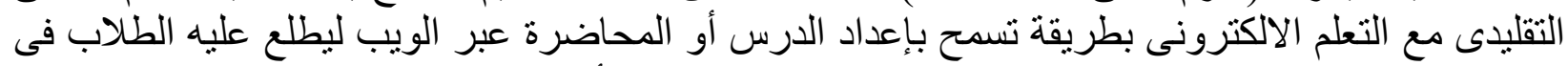

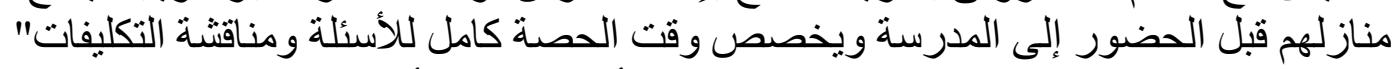

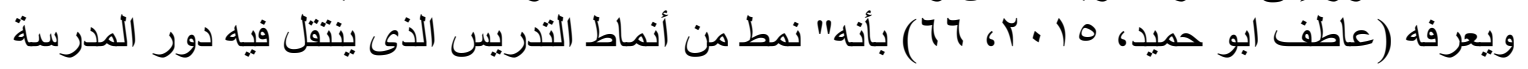
إلى دور الاسرة فى التعلم التقليدى وما يتم عمله فى البيت فى التعلم التقليدى يتم فى المدرسة فئ في التعلم

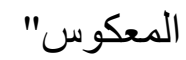

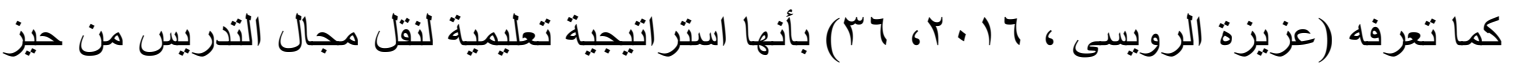

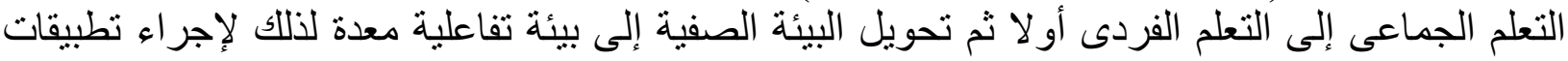

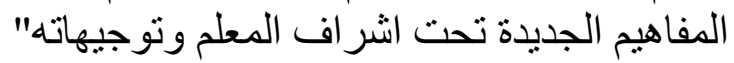
بيئة تفاعلية عبر الويب (الو اتس اب و الفيس بوك) بين المعلمة و الو الدين لمشاركة مقاطع فيديو أفلام تعليمية

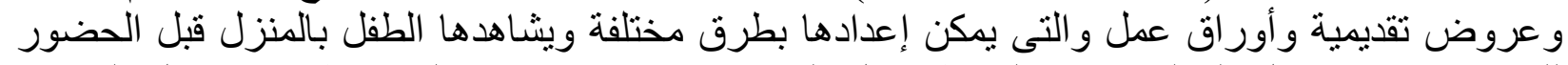

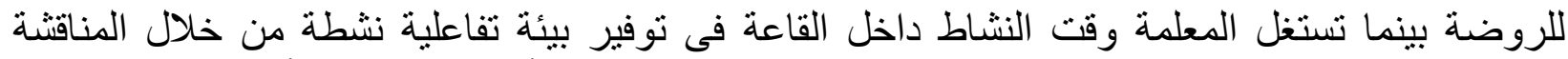
و الحوار وتطبيق ما تعلموه"من خلال العرض السابق للتعريفات نجد أن هنالك ركائز أساسية يستند علئه تليها التعلم المعكوس هى: ا ـ البيئة التعليمية المرنة فى انظمتها وتعدد خيار اتها فى أساليب التدريس و التقويم.

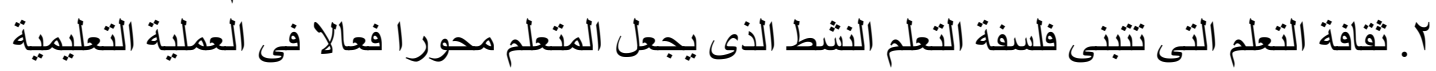
ץ. المحتوى الدراسى المصمم فى ضوء آلية تطبيق التعلم المعكوس المنظم والمدعم بالاستر اتيجيات المتمركزة حول المتعلم و إستر اتيجيات التعلم النشط.

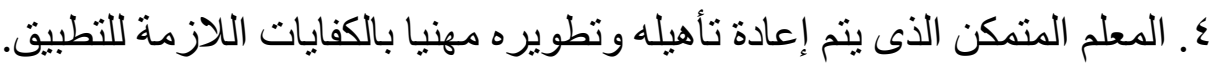

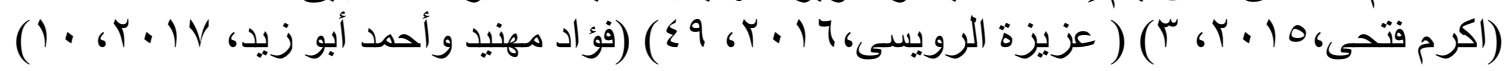

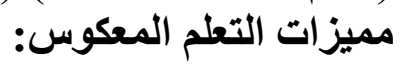
من خلال الدر اسات و التجارب المعكى التى طبقت التعلم المعكوس كاستر اتيجية تعليمية ذكرت إيجابيات منها:

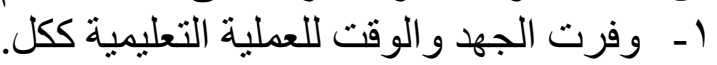

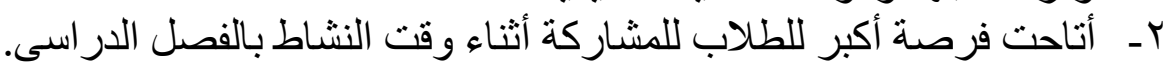

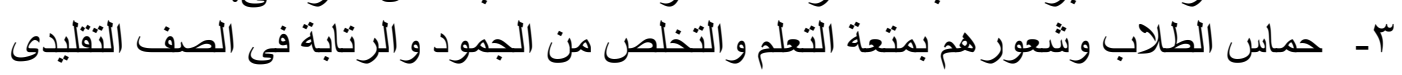

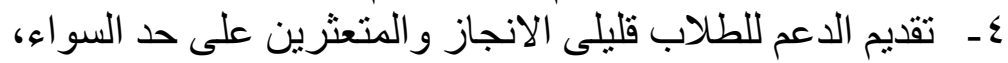

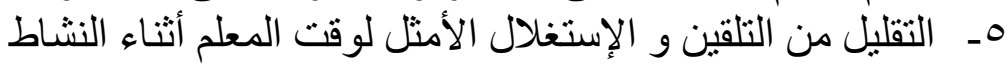

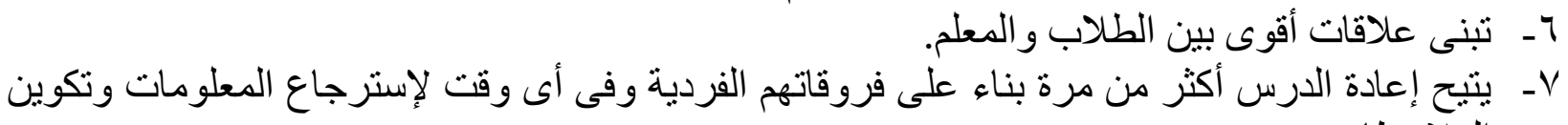
الملاحظات.

^- سد الفجوة المعرفية التى يسبيها غياب الطلاب عن المدرسة.

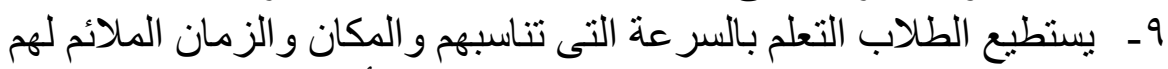

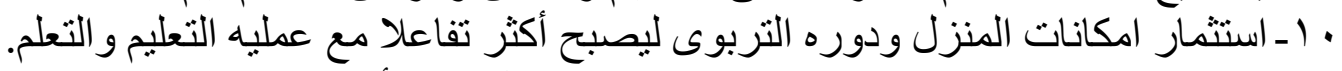

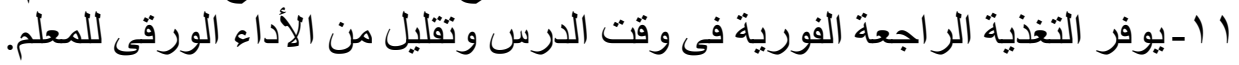

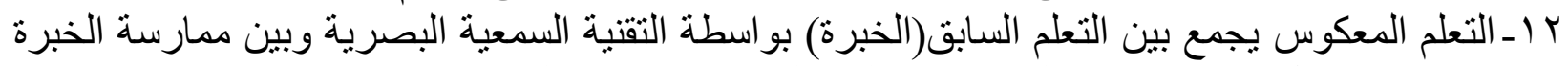

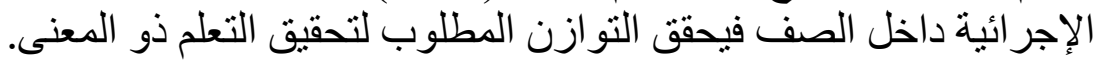

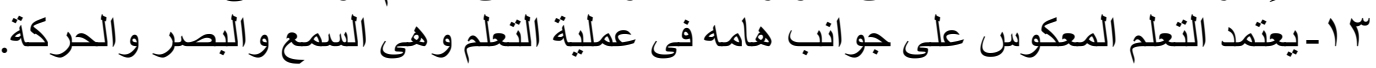

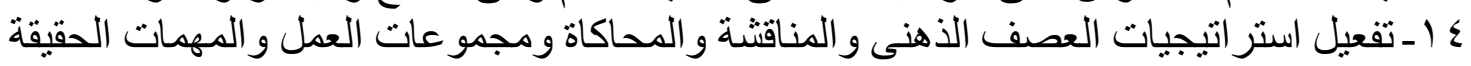

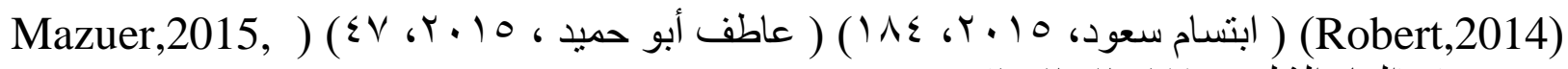

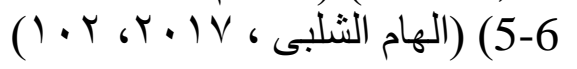


أهداف التعلم المعكوس فى رياض الأطفال:

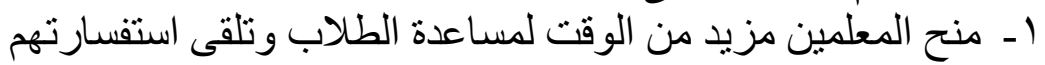
r بـ بناء علاقات أقوى بين الطفل و المعلمة.

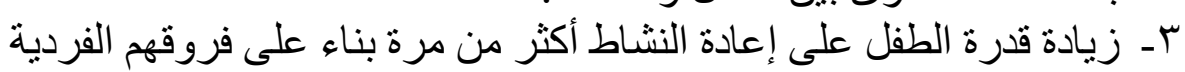

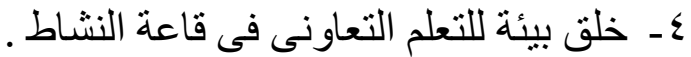
هـ تطبيق التعلم النشط بكل سهولة.

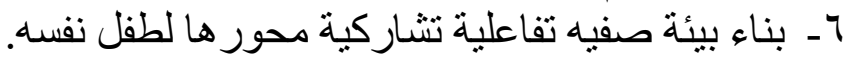

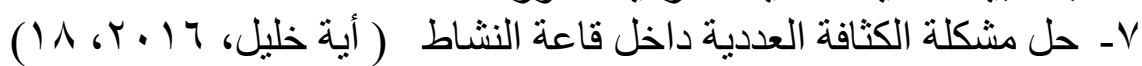

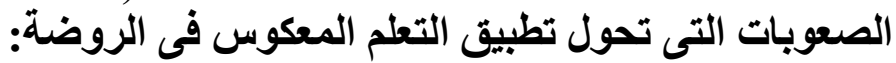

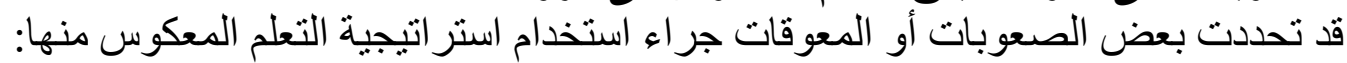

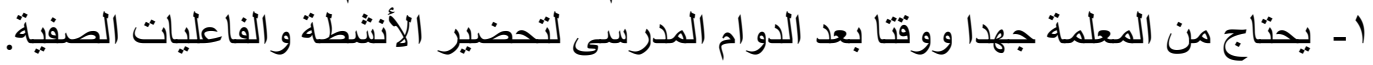

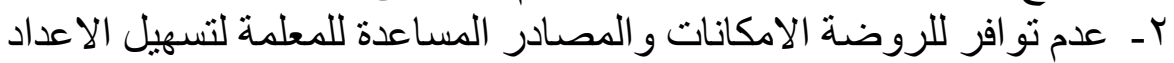

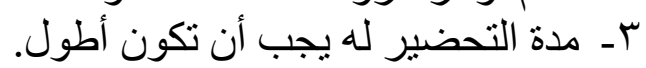

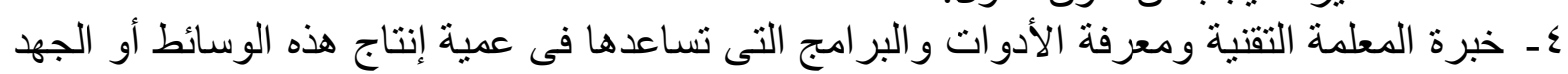

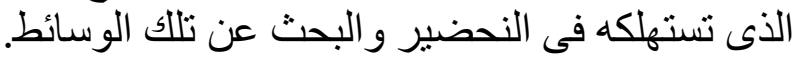

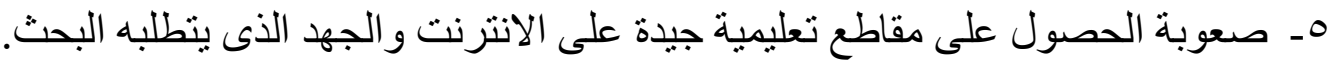

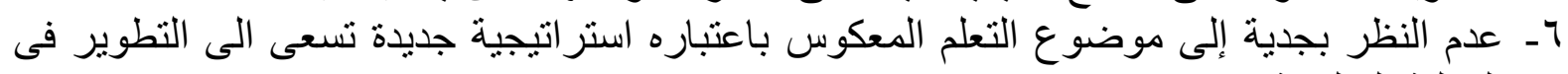

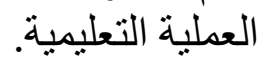
V- - صعوبه التحول من طريقة التعلم التقليدية التى تقوم على المحاضرة من قبل المعلم وعلى استذكار

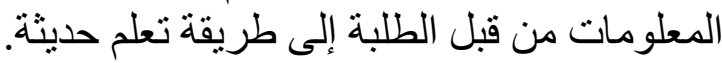

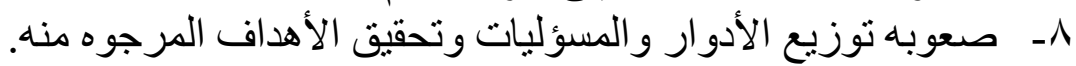

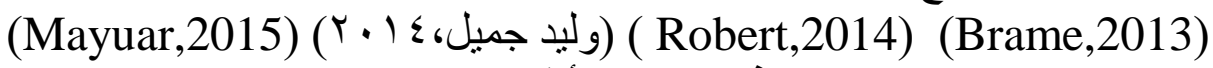
معايير استخلام التعلم المعكوس فى رياض الأطفال:

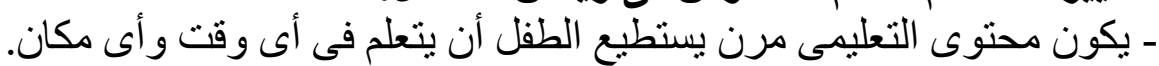

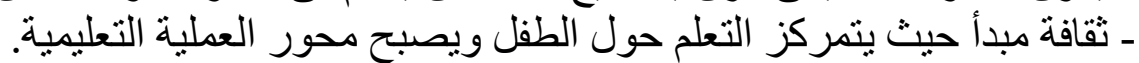

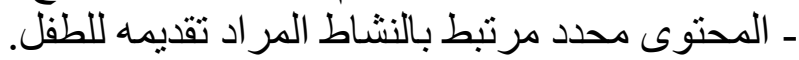

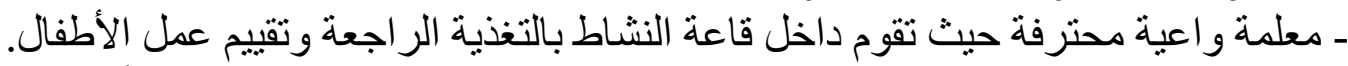

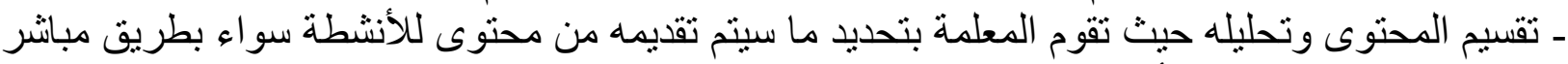

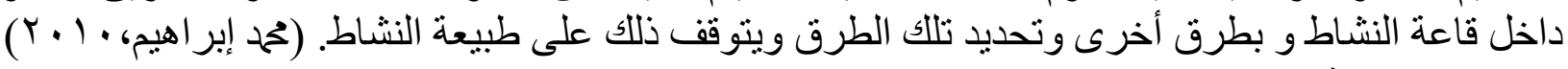

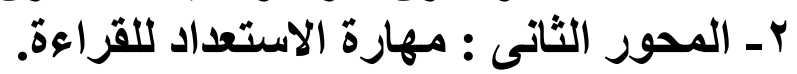

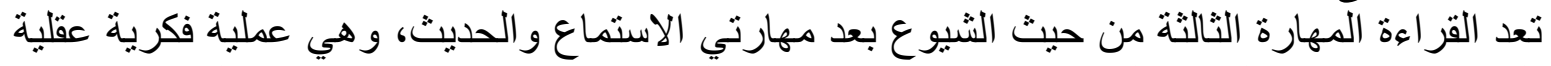

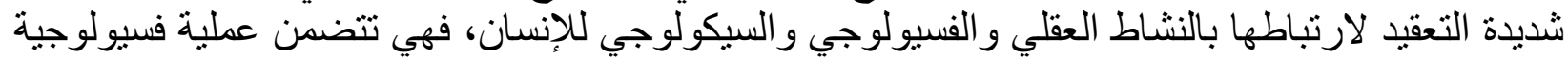

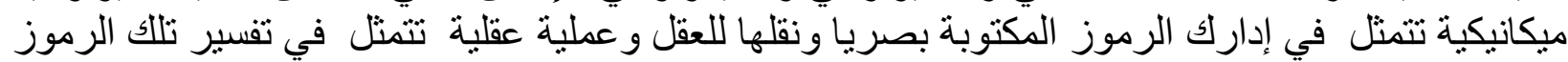

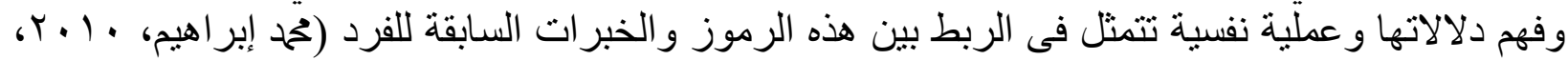

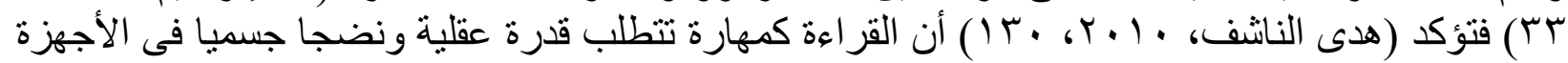

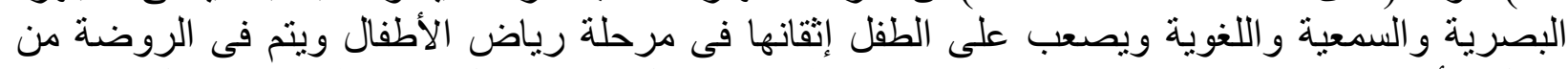

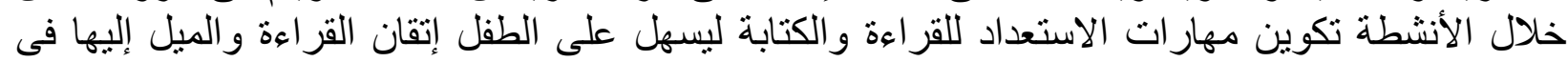
المدرسة الابتدائية .

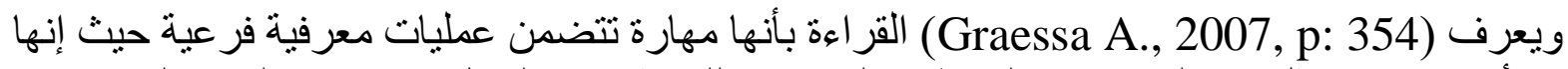

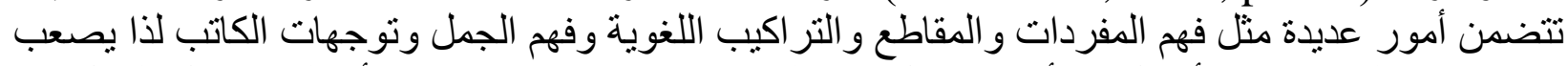

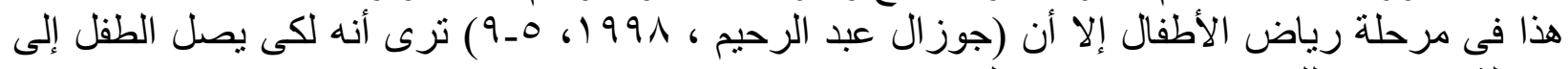

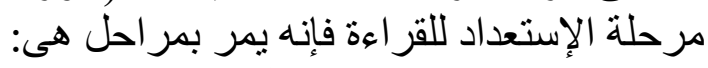

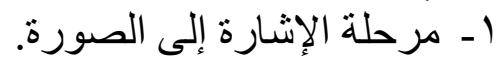




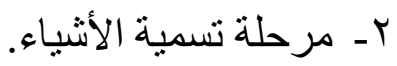
r- ــ مرحلة ارتباط الصورة بالأحداث و التعبير عنها فى جمل بسيطة.

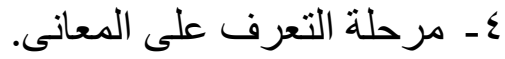

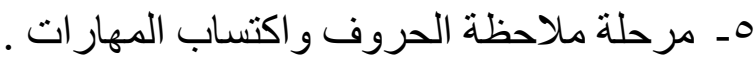

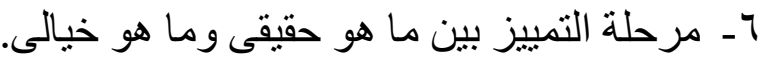

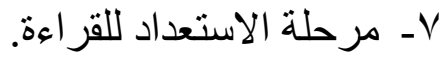

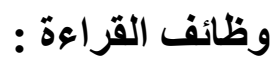

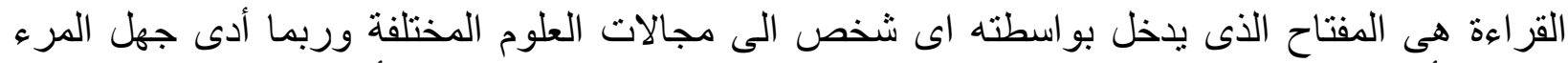

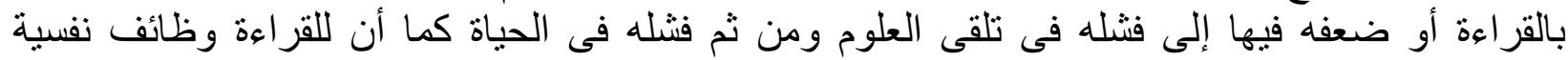

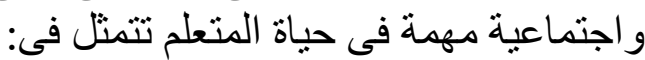

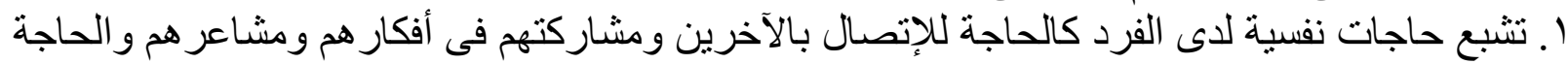

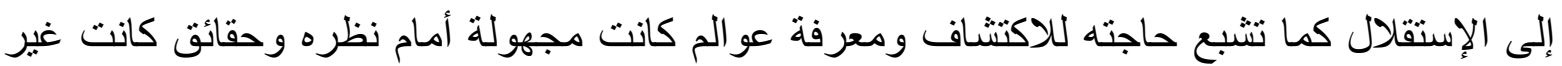

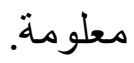
r. تساعد القراءة الإنسان على التكييف النفسى اذا يمكن أن تكون ملجا للتنفيس عن بعض الضغوط النفسية فالقر اءة تخلص الفرد من عناء الانفعالات الأكان.

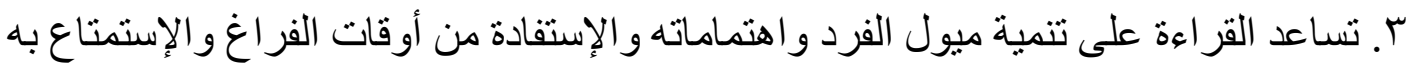

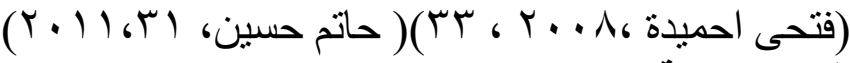

استراتيجيات تنمية مهارة الإستعداد للقراعة لاى طقل الروضة:

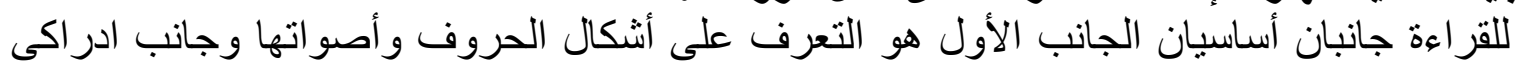

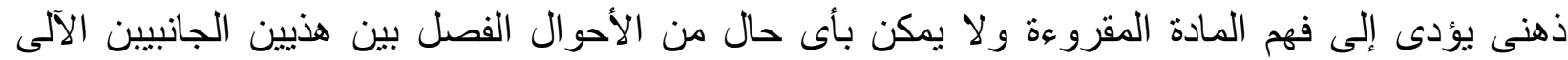

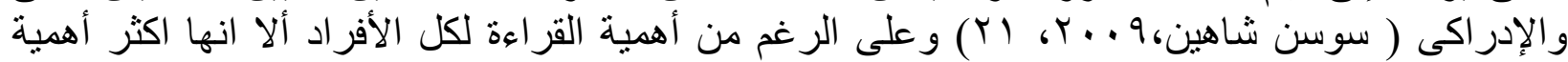

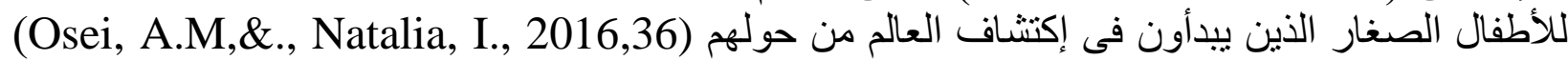

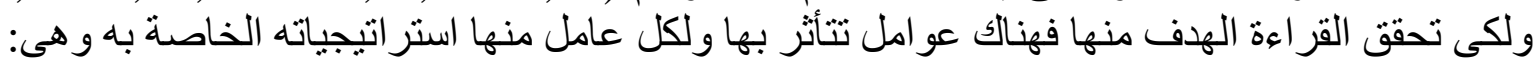

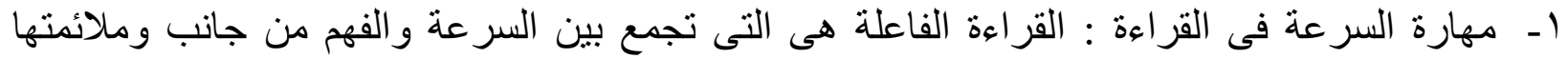

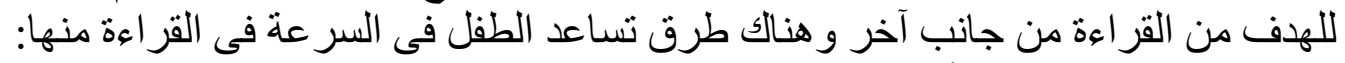

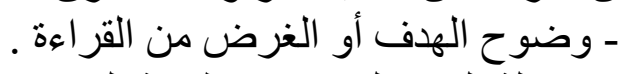

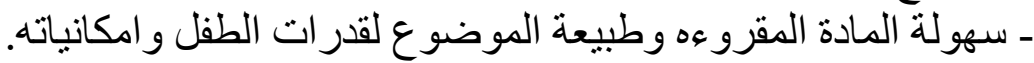

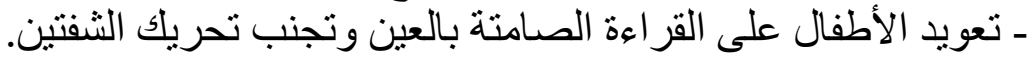

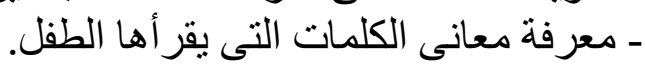

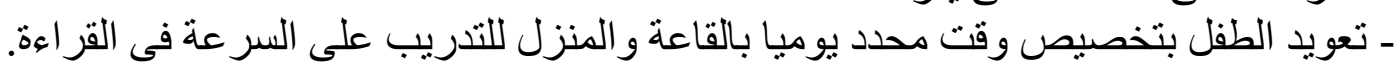

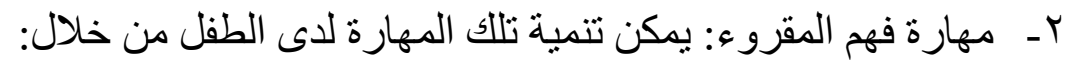
ـ تنمية التروة اللغوية (المفردات ) عن طريق الكتساب معانى ومفردات جديدة وتتمية تلك الكات

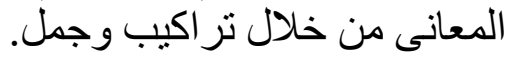

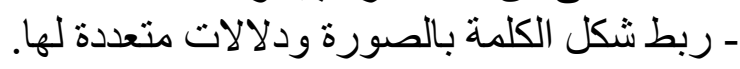

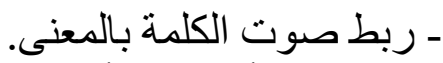

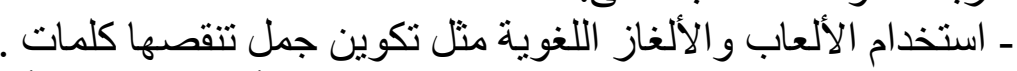

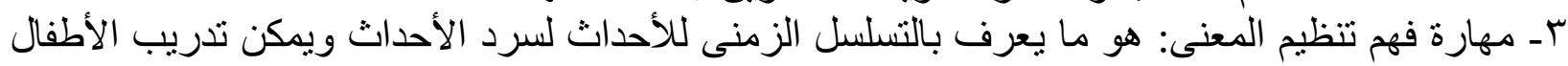

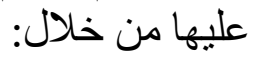
ـ ـ ـ إستخدام مفردات التسلسل مثل قبل، وبعد ، ثم، او لا، ثانيا....

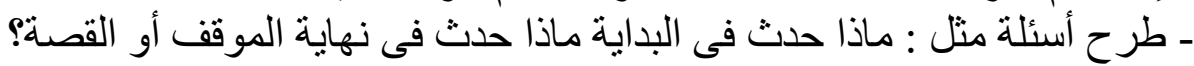

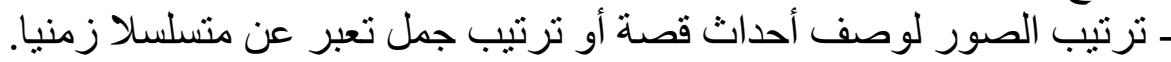

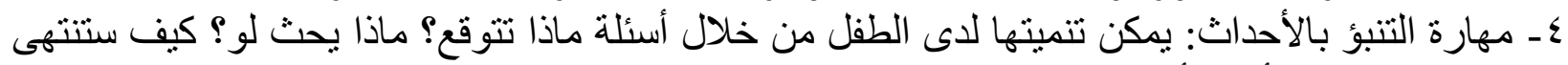

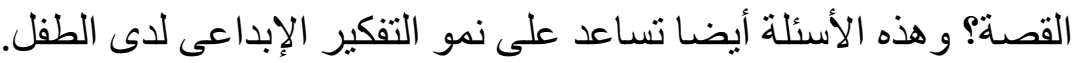


هـ تفسير المشاعر وتحليلها: يمكن تنميتها لدى الطفل من خلال قر اعة قصة بشكل معبر عن تعبير ات الوجه

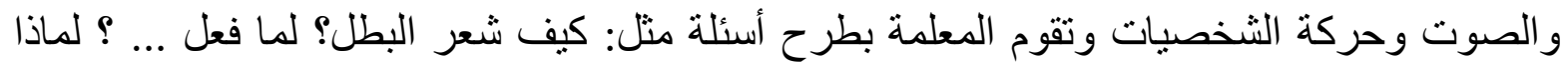
فعل...

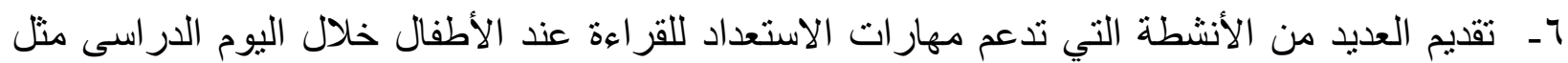

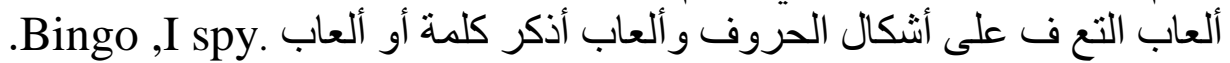

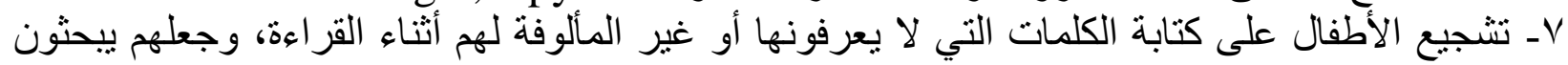

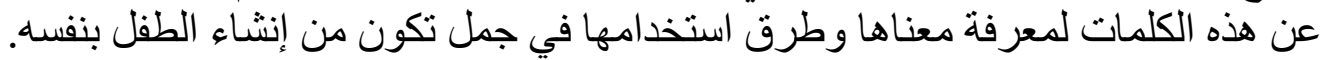

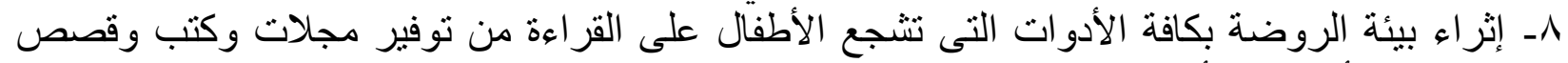

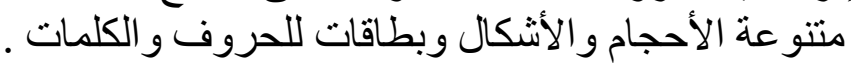

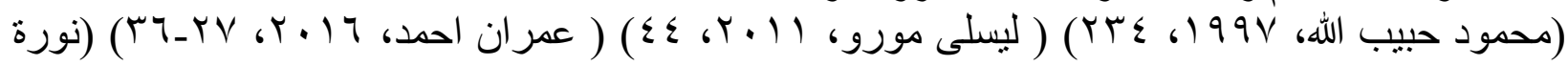

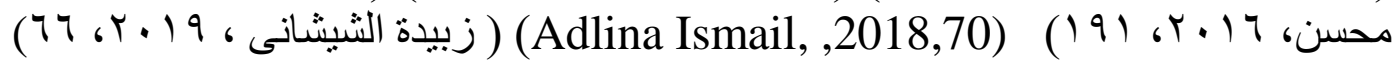
(Mary Gannon,2019,40) سابعا : إجراعات المنهجية: (1) إستخدم البحث الحالى المنهج شبه التجريبى ذو المجموعة الواحدة لمناسبته للبحث ، حيث بـثيث يتيح

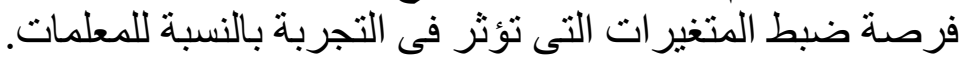

(r) عينة البحث: تم التطبيق على عدد (·r) طفل بالمستوى الثانى لرياض الأطفال بمدرسة الهلال الأحمر الرسمية لغات بادارة البساتين ودار السلام بمديرية التربية وانية والتعليم بالقاهرة.

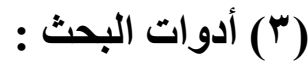
- ق قامت الباحثة بتطبيق برنامج الانشطة للمهارة القراءة باللغة الانجليزية القائم على التعلم المعكوس للأطفال.

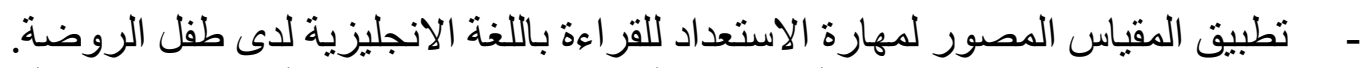

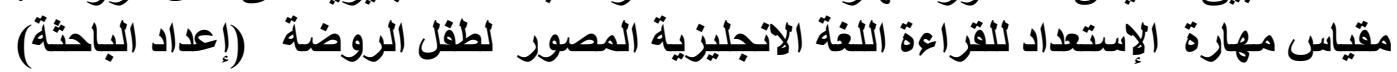

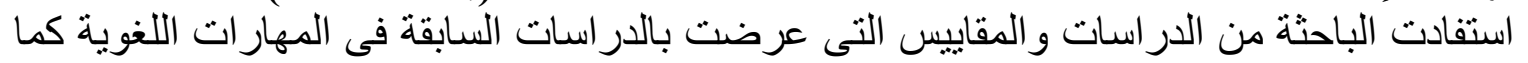

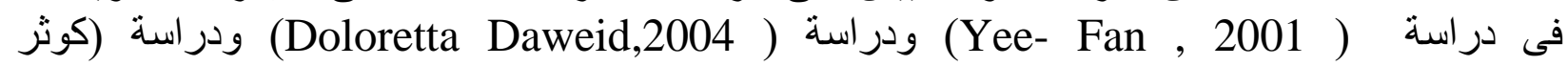

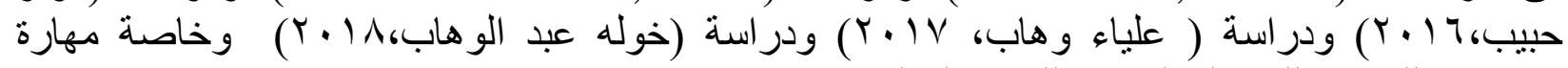

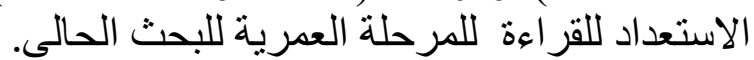

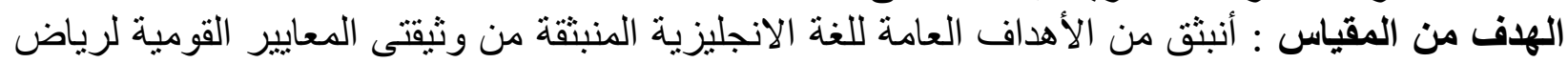

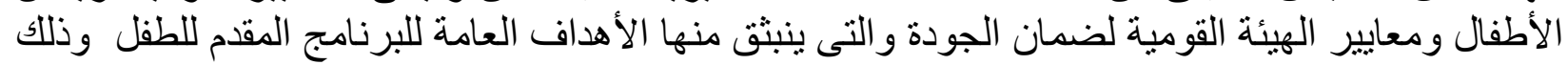

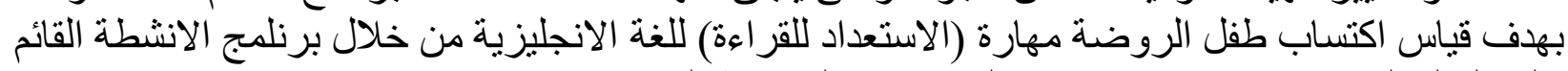

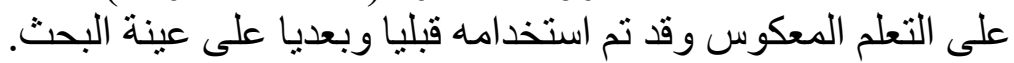

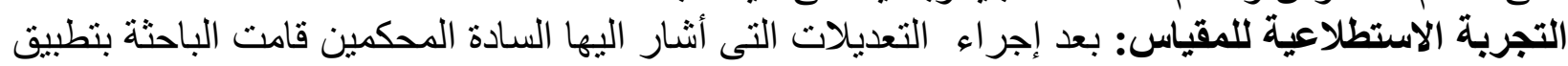

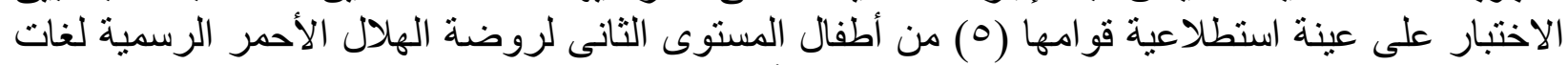

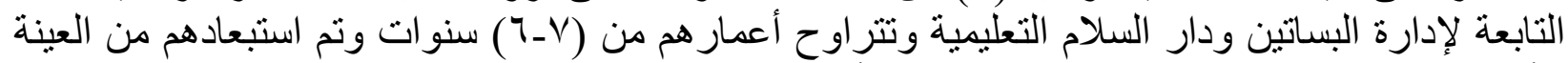

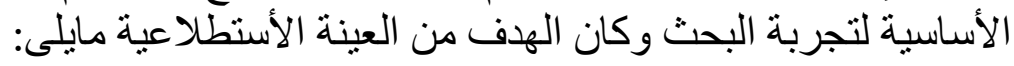

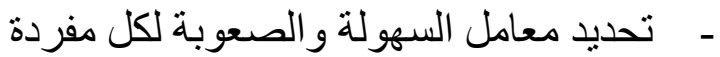
- صدق وثبات المقياس. - مدى وضوح الصور وقدرة الأطفال على فهمها 
الخصـائص السـيكومترية لمقيـاس مهـار ات اللغـه الانجليزيـة : قامــت الباحثـة بايجـاد معـاملات الصـدق

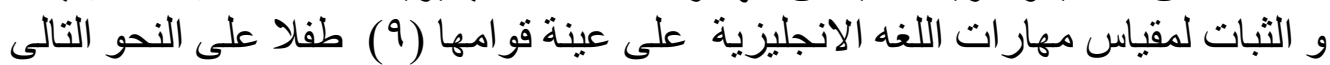

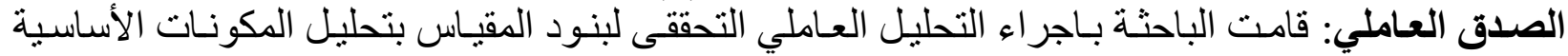

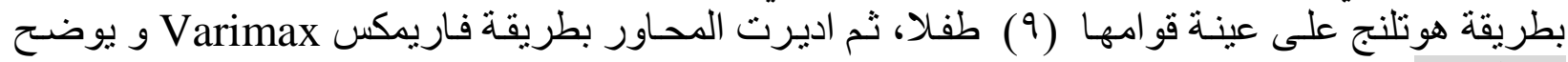

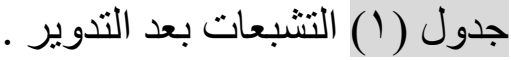

جدول (1) التثبعات الخاصة بالعامل الثالث ( الاستعداد للقراءة)

\begin{tabular}{|c|c|c|}
\hline التشبعات & 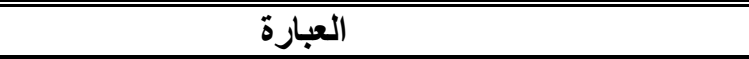 & رقم العبارة \\
\hline.. $\mathrm{VI}$ & اختار الكلمة الصحيحة من: House- esuoh- ouseh & Ir \\
\hline$\therefore v$. & اختار الصورة الدالة عن الكلمة (garden) & 14 \\
\hline . & $\begin{array}{r}\text { (ختار الصورة الدالة عن الكلمة } \\
\text { (Wash face ) }\end{array}$ & $1 \leq$ \\
\hline$\cdot .7$ & وصل الجملة بالصورة الدالة عليها: & 10 \\
\hline .01 & 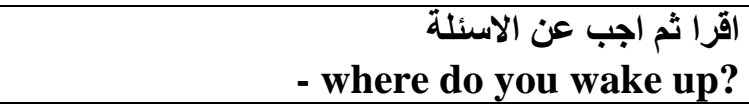 & 17 \\
\hline..$r r$ & اقرا ثم اجب عن السؤال: & IV \\
\hline r.19 & الجذر الكامن & \\
\hline$\% 9.94$ & نسبة التباين & \\
\hline
\end{tabular}

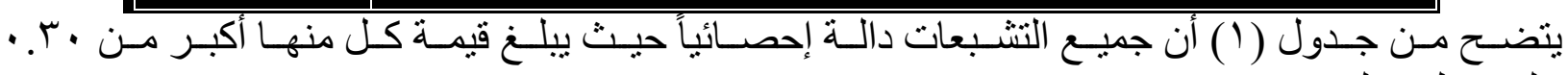
على محك جيلفورد. معامل الثبات ألفا بطريقة كرونباخ: قامت الباحثة بإيجاد معـاملات الثبات لمقيـاس مهار ات اللغـه الانجليزيـة

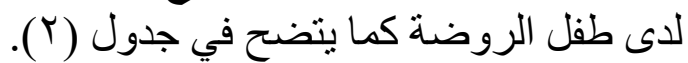
جدول (Y) معامل الثبات م بطريقة كرونباخ

\begin{tabular}{|c|c|}
\hline معامل الثبات ألفا & الأبعاد \\
\hline. .19 & بالاستعداد للقراعة (مهارات ما قبل القراعة) \\
\hline
\end{tabular}

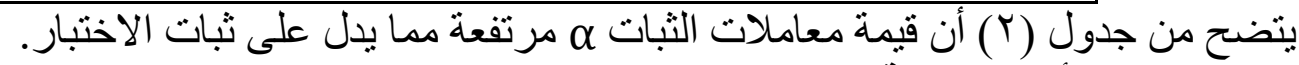

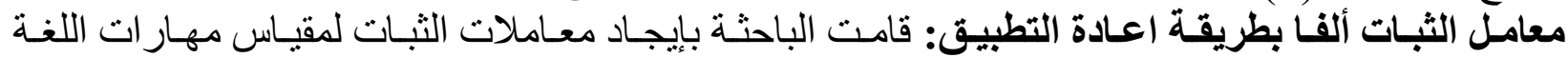

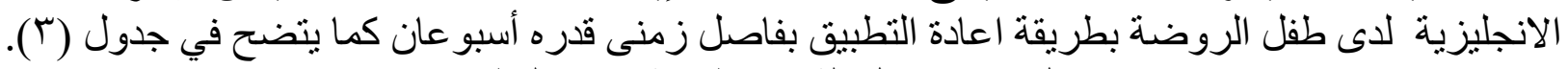
جدول (T) معامل الثبات بطريقة اعادة التطبيق

\begin{tabular}{|c|c|}
\hline معامل الثبات ألفا & الأبعاد \\
\hline. .94 & بالاستعداد للقراءة (مهارات ما قبل القراءة) \\
\hline
\end{tabular}

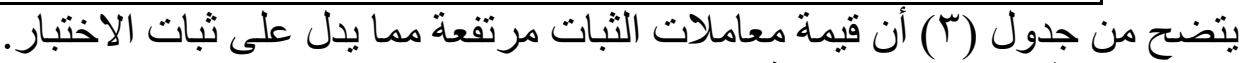

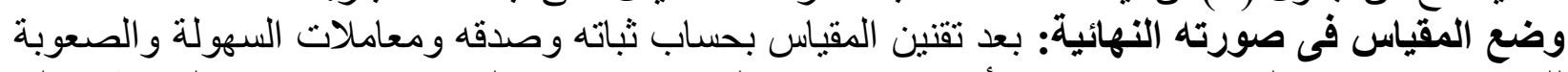
للمفردات و إجر اء التعديلات فى ضو فه أر أه اء ومقترحات المحكمين اصبح المقياس فى صورته النهائية صالح لمرحلة التطبيق على عينة البحثي. يوضح جدول (ع) مفردات مهارة الاستعداد للقراءة والرقم الدال عليه فى المقياس وتقدير الدرجات للمقياس موزعة كالآتى : 
جدول (؛) توزيع عدد مفردات مقياس مهارات اللغه الانجليزية المصور (مهارة الاستعداد للقراءة) و الارجات

\begin{tabular}{|c|c|c|c|c|}
\hline عدد الدرجات & رقم المفردة & عدد المفردات & المهارة & r \\
\hline r درجات & $r_{-1}$ & التمييز البصرى للكلمات & \multirow{3}{*}{ القراءة } & 1 \\
\hline " & $\varepsilon-r$ & التعرف والفهم . & & $\overline{T r}$ \\
\hline r درجات & $7-0$ & القزاءة الجهرية السليمة & & $\bar{\mu}$ \\
\hline
\end{tabular}

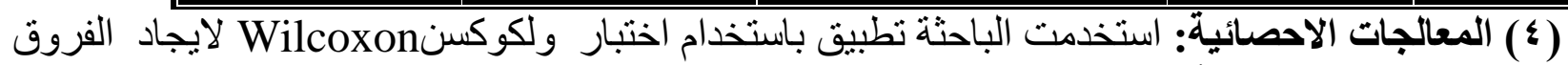

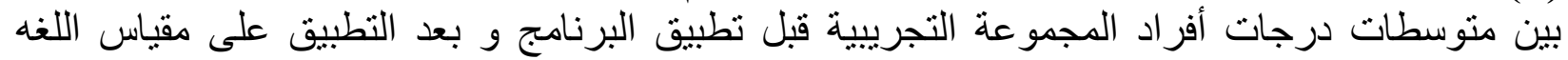

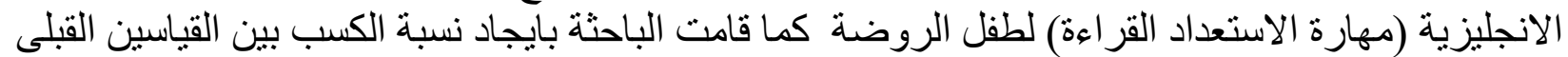

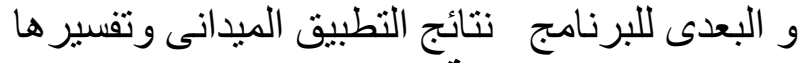

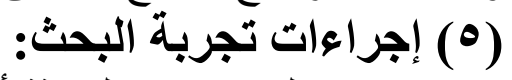

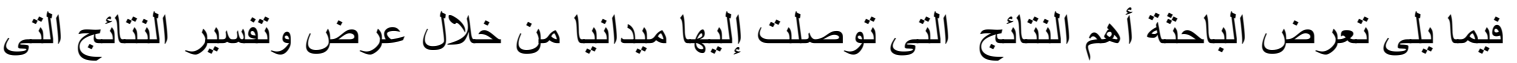

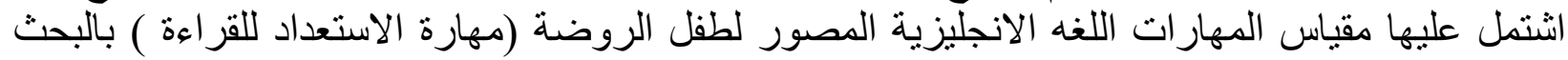

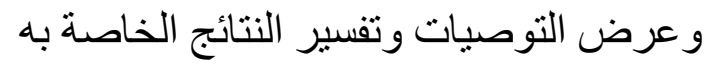

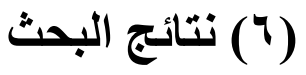

إختبار صحة الفرض الإى ينص على أنه : "توجد فروق ذات دلالة إحصائية بين متوسطى

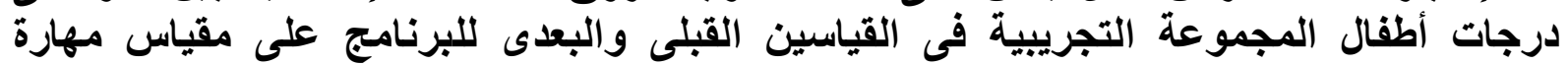

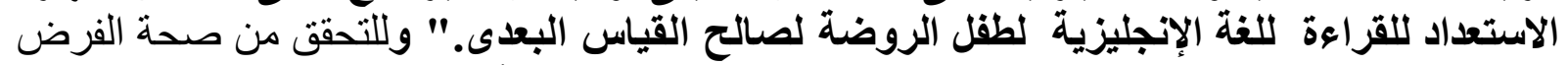

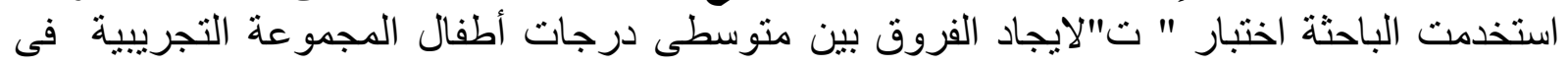

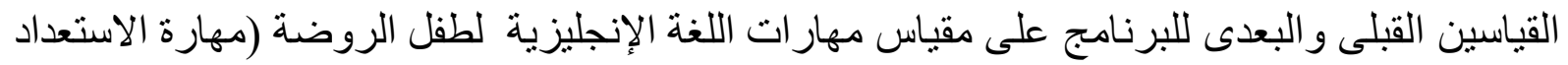

$$
\text { للقراءة) كما يتضح فى جدول (0) }
$$

جدول(ه) الفروق بين متوسطى درجات أطفال المجموعة التجريبية فى القياسين القبلى والبعدى (لإني

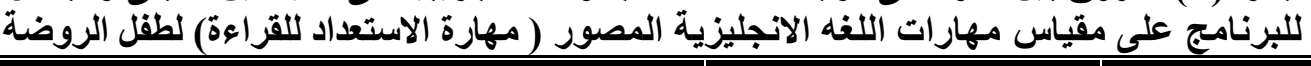

\begin{tabular}{|c|c|c|c|c|c|}
\hline \multirow{2}{*}{ اتجاه الدلالة } & \multirow[t]{2}{*}{ مستوى } & \multirow{2}{*}{ ت } & \multicolumn{2}{|c|}{ القياسين القبلى و البعدى } & \multirow{2}{*}{ المتغيرات } \\
\hline & & & مي ح ف & م ف & \\
\hline فى اتجاه القياس البعدى & دالة عند & Y..01 & $\cdot \wedge \leq \leqslant$ & \&. 1 & 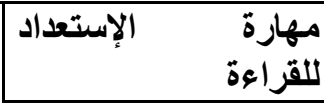 \\
\hline
\end{tabular}

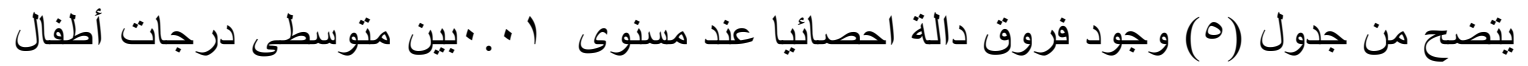

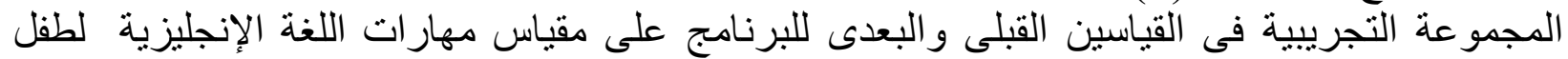
الروضة فى إتجاه القياس البعدى.

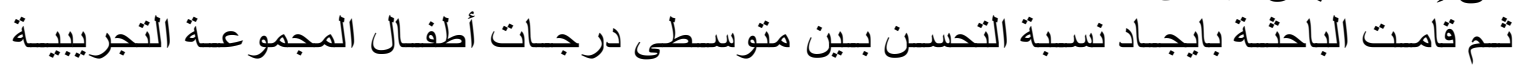

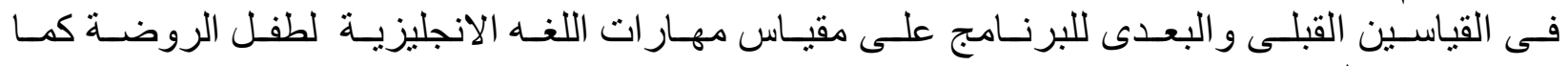

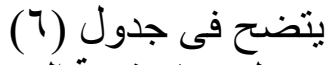

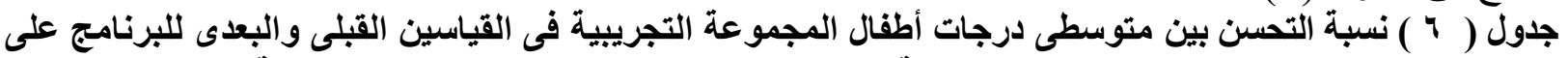

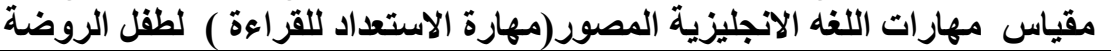

\begin{tabular}{|c|c|c|c|}
\hline نسبة التحسن & القياس القبلى & القياس البعدى & المتغير ات \\
\hline$\% \wedge$. & $1 . \varepsilon$ & 0.0 & مهارة الاستعداد للقراعة \\
\hline
\end{tabular}


ا. إحتو اء برنامج الأنشطة على أنشطة تحفز طاقات الطفل لاطلاق أقصى قدراته واستحداث استخدامات جديدة للتكنولوجيا غير مألوفة مما ساعد الأطفال على إطلاق حرية تفكير هم وتحدثهم بطلاقة وسهوله

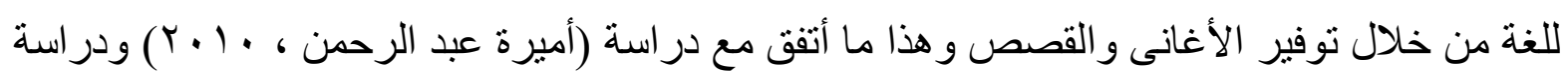

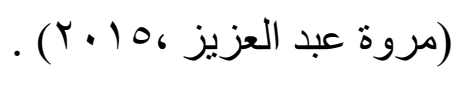

r. ممارسة أنشطة الغناء والمحادثة واللعب وتوظيفها أثشعر الأطفال بالإنجاز ومن هنا أسهم فى تكوين اتجاهات ايجابية نحو تعلم مهارة القراءة خاصة انه من خلال اطار عام ر يخرج عن عن الحياة اليومية

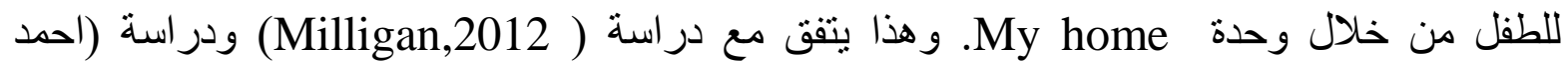

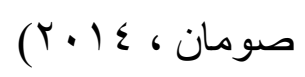

rا إستخدام التقنيات الحديثة فى تقديم محتوى الأنشطة إلى الأطفال كالإعتماد على الحركة والأصوات

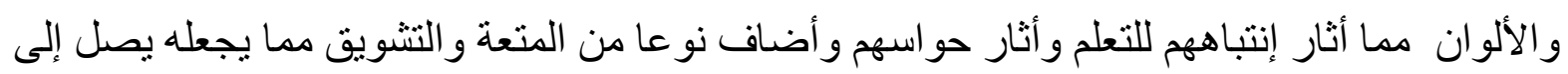

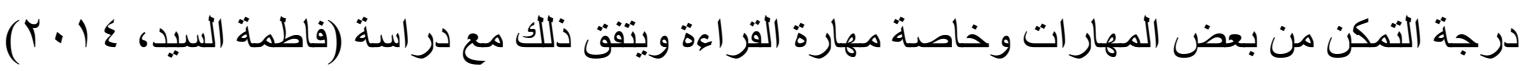

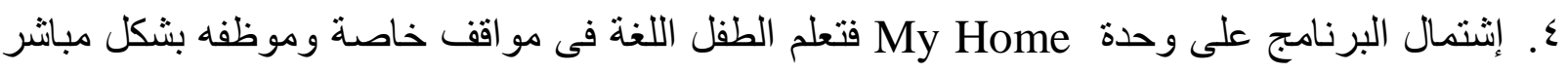

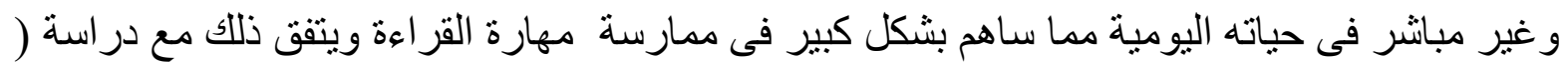

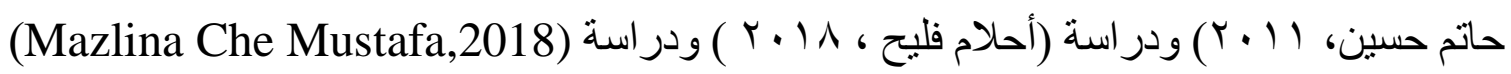

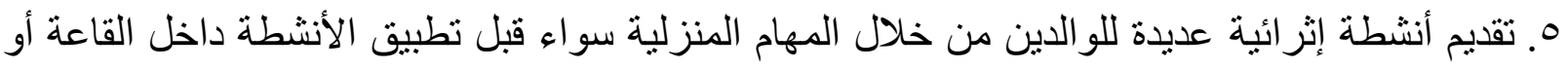

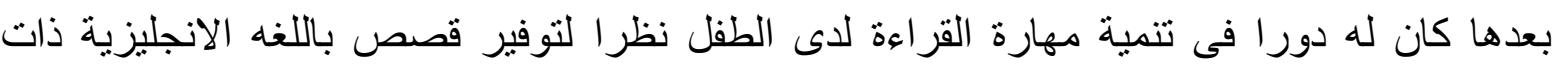

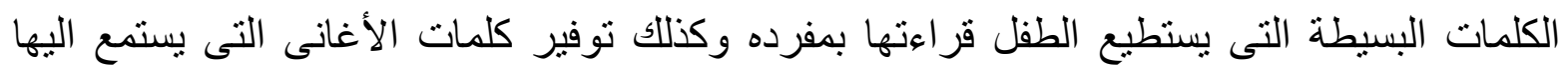
الطفل ساعده على قر اءة الكلمات وربطها بالمحتوى المسموع و ويتفق ذلك مع دراسة (أمانى محمود،

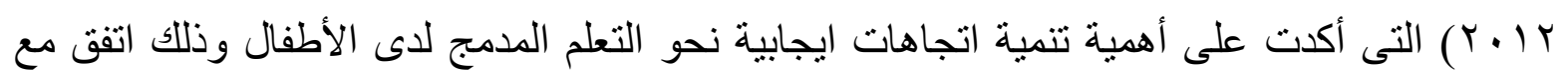
دراسة (Thelal Iqab Owei 2018) T. قدم البرنامج الأنثطة التعليمية لممارسة اللغة عن طريق المشاركة والتفاعل داخل القاعة ومن خلال

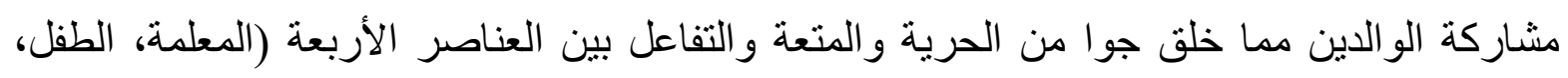

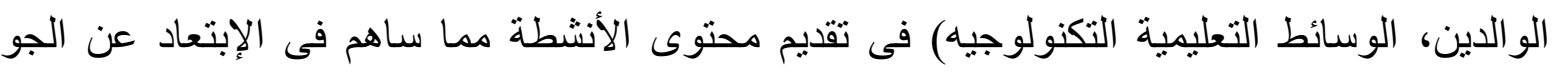

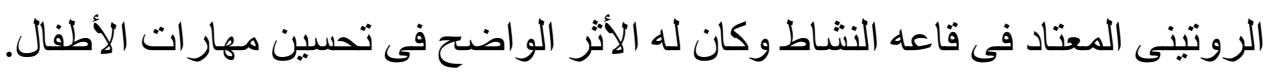

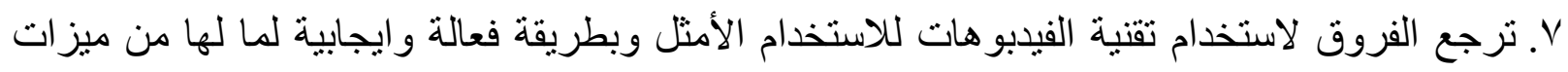

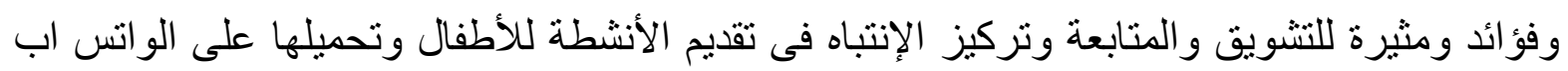

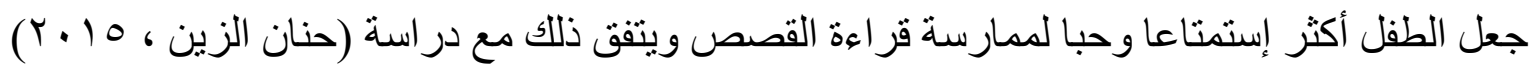

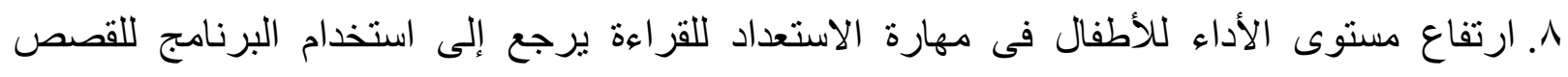

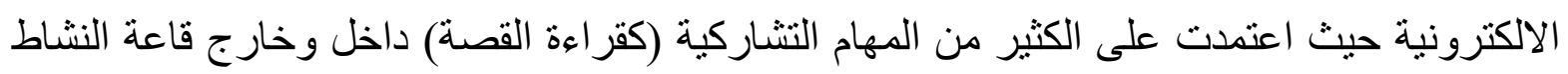


من خلال قراءة القصة والتعبير عنها بالكلمات البسيطة وكذلك تبادل الخبرات بين الأطفال بعضهم

$$
\text { توصيات البحث: من خلال جروب الواتس اب. }
$$

ا. ضرورة العمل على تدريب المعلمات قبل و أثناء الخدمة على فهم تطبيقات التعلم المعكوس مما يساعد على تتمية المهار ات لدى المعلمة أثناء الإعداد الأكاديمى لها بكليات رياض الأطفال و أقسام التربية

$$
\text { الطفل بكليات التربية . }
$$

ץ. ضرورة البدء فى إعداد بر امج تدريبية للمعلمات أثناء الخدمة ليست فقط تهدف إلى تنمية مهار ات اللغة الانجليزية لايهن إنما تساعدهن على تقديم مناهج اللغة الإنجليزية المقررة لأطفال الروضة. r. تأسيس ثقافة جديدة لدى المعلمات تقوم على التعلم متعة وذو معنى.

ع. ـعريف المعلمات باستر اتيجية التعلم المعكوس فى جميع المستويات ولكافة المر احل الدر اسية. •.عمل بر امج تدريبية تاهيلية للمعلمات قائمة على تطبيق نماذج التعلم المعكوس للاستفادة منها فى جميع

$$
\text { مجالات المنهج المقدم للطفل }
$$

7 7. إجر اء مزيد من الدر اسات فيما يتعلق بأهمية استر اتيجية التعلم المعكوس ودمجها بعملية التعلم. V. . دعم وتدريب المعلمين فى كافة المراحل التعليمية وفى مختلف التخصصات على إستخدام المشاركة الو الدية الفعالة فى الروضة 


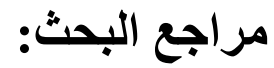 \\ أولا: المراجع العربية: - مراجع}

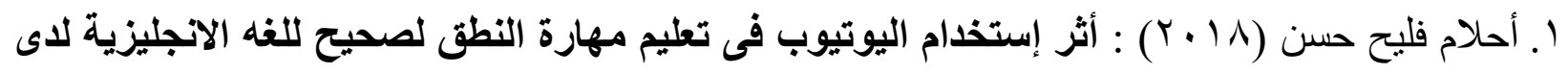
اطفال الروضة فى المدارس الخاصة بمحافظة العاصمة عمان، رسالة ماجسنير ، كلية العلوم التربوية،

$$
\text { جامعه الثرق الاوسط. }
$$

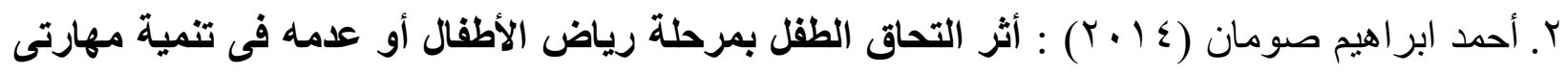

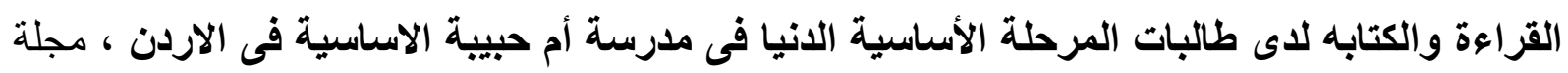

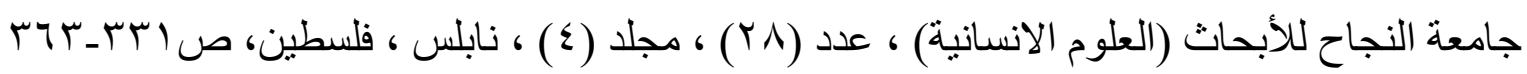

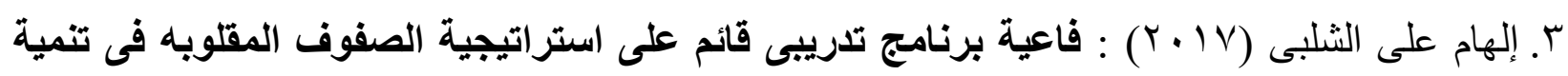

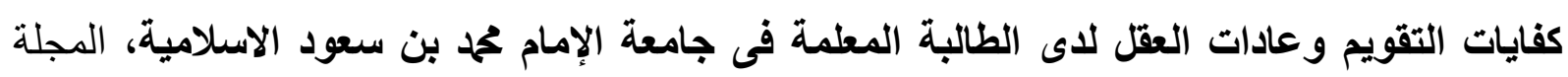

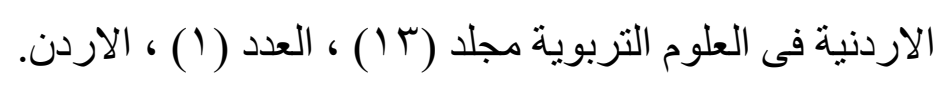

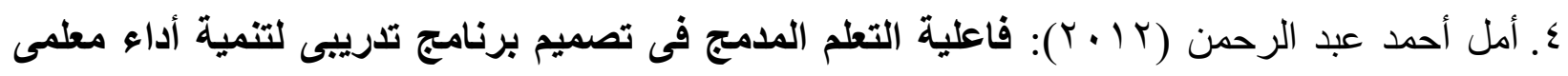
العلوم بالمرحلة الاعدادية فى ضؤء معايير الجودة، ماجستير غير منشورة، كلية التربية ، جامعه طنطا.

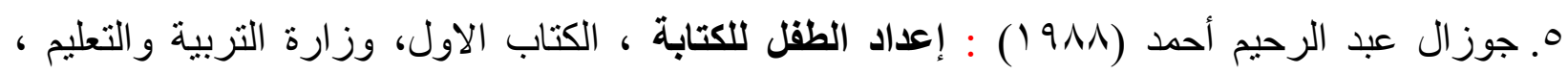
القاهرة.

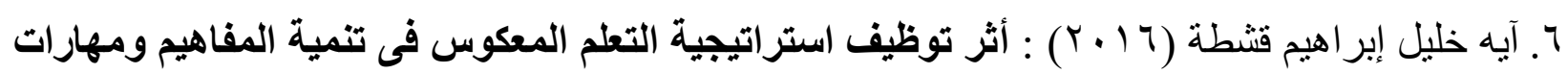

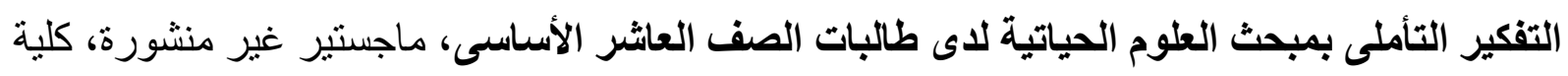

$$
\text { التربية، الجامعه الاسلامية، غزة. }
$$

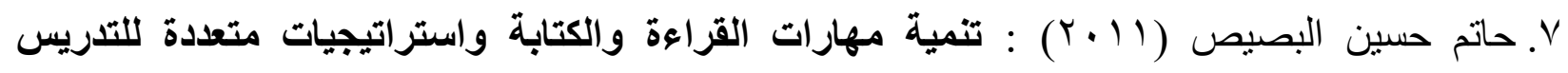

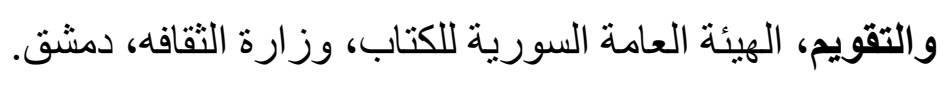

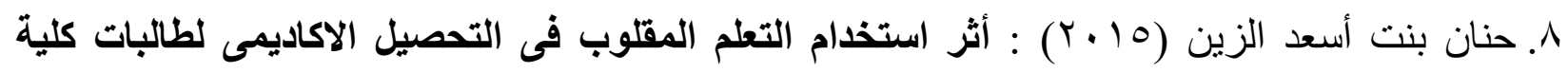

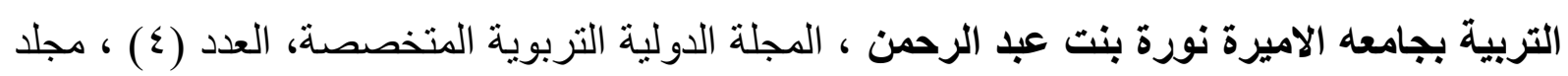

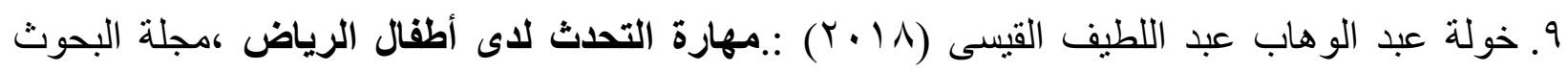

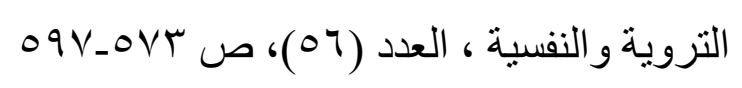

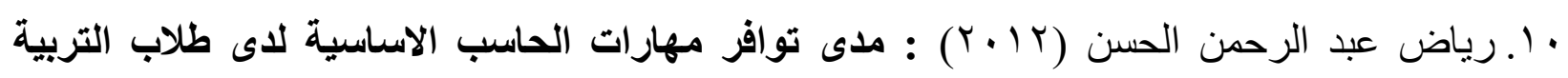

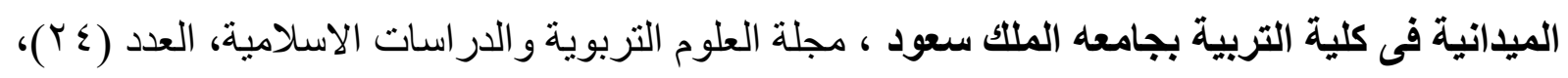
مجلد(ب)، الرياض، المملكة العربية السعودية. 
1) سوسن الثخرينى شاهين (9 . . r) : أثر برنامج مقترح فى تنمية بعض مهارات القراءة لدى تلاميذ الصف الثالث بمدارس وكالة الغوث الدولية بشمال غزة، رسالة ماجستير في التربية، الجامعه الاسلامية،

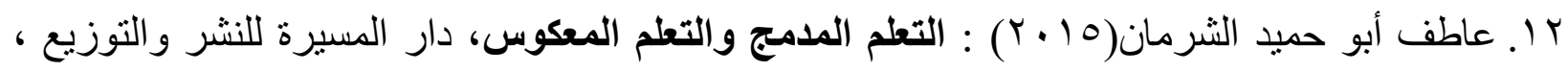
عمان. (- n

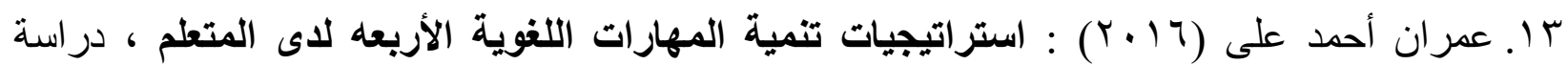

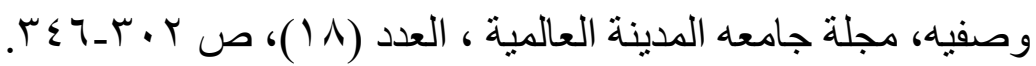

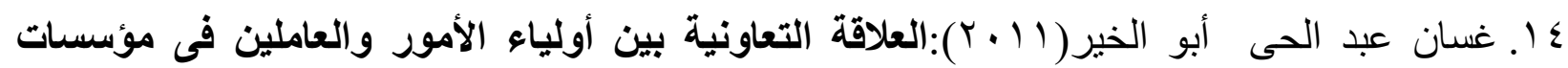

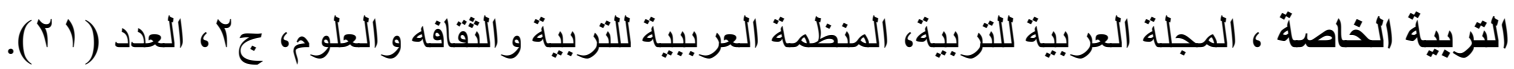

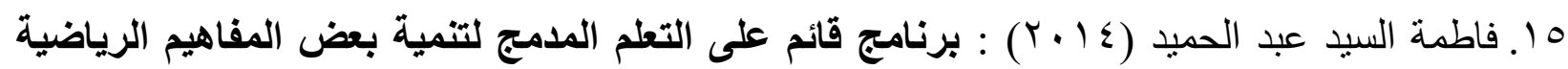

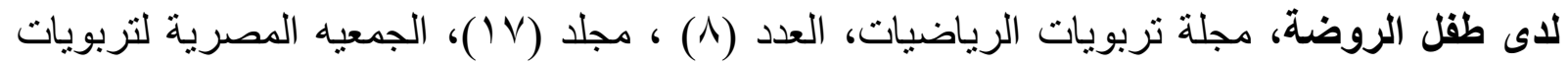

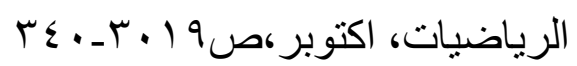

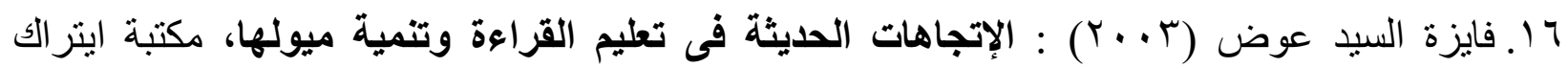
للطباعه و النشر و التوزيع ، القاهرة.

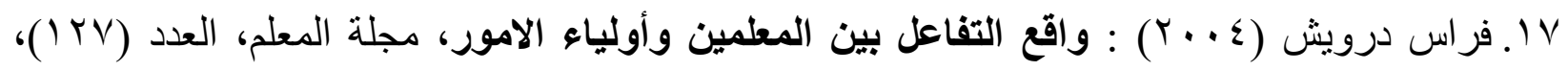

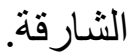

1 ا. فتحى ححم احميدة (1 . ㄷ) : درجة تقدير معلمات رياض الأطفال لممارستهن فى اعداد بيئة تعليمية

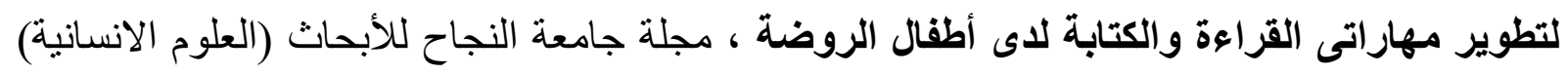

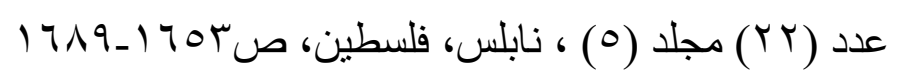

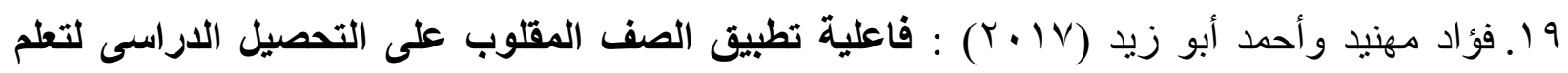

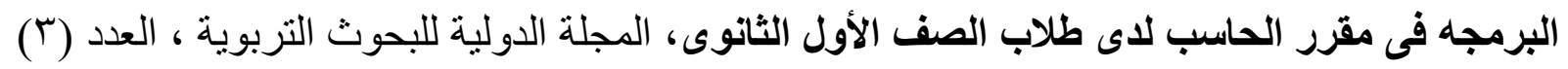

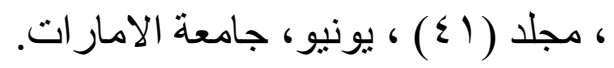

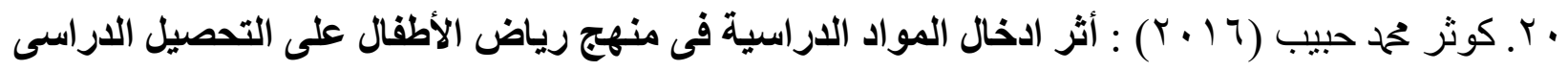

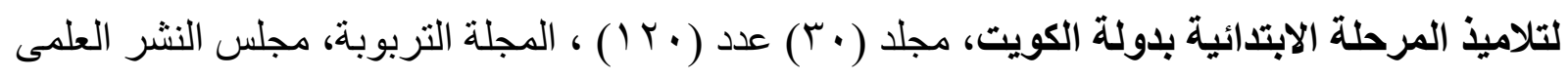

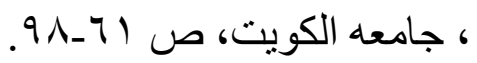

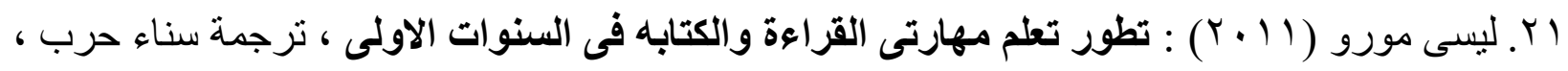

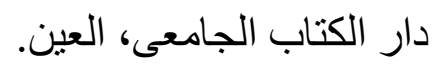

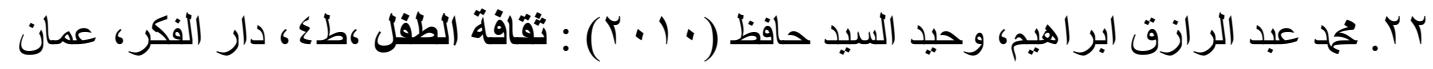


rr. تحمح رجب حبيب الله (997) ) أسس القراءة وفهم المقروء بين النظرية والتطبيق، دار عمان،

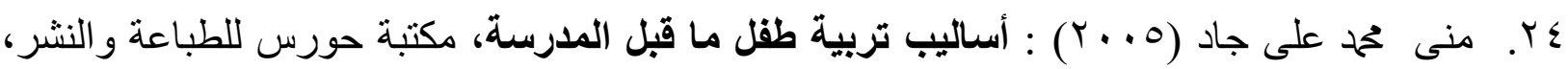

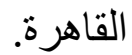

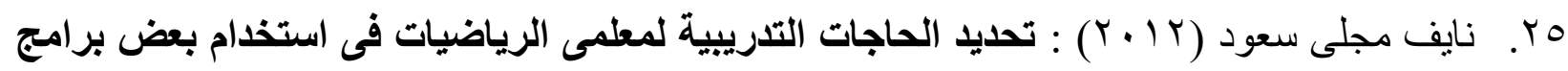

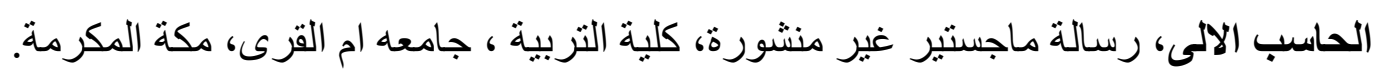

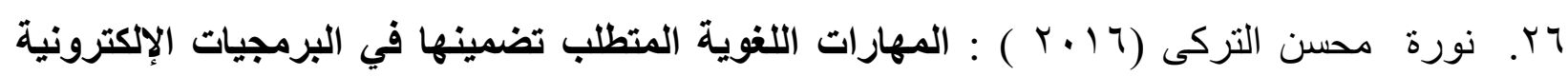

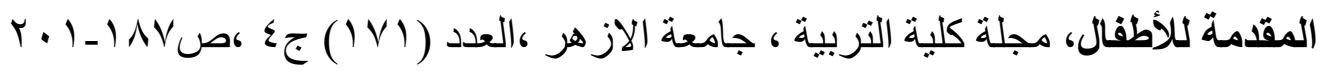

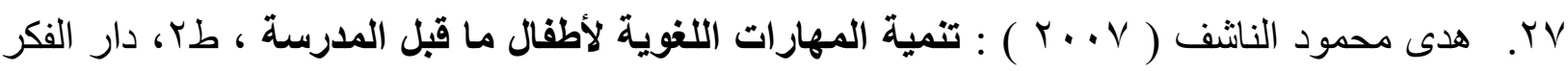

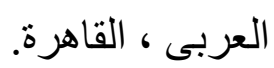

ثانيا:المراجع الأجنبية:

28 - Adlina Ismail, Normah Yusof (2018). Malaysian Children Storybooks as ESL Reading Materials. International Journal of Education \& Literacy Studies. Volume: 6 Issue: 3.p 68:75

29- Alshumaimeri Y., \& Alhessan R., (2013): Current Availablity and use of ICT Among Secondary EFL Teacher in Sudi Arabia Possibilities and Reality, Journal of Educational Sciences 25(1) , P: 227-240.

30- Dploretta Dawuid (2004): A Whole Language Approach for Foreign Language Writing Using Computers, ph. Dissertation state University of New York Stong Brook.

31- Graesser A.,R., (2007) : A reading comprehension strategies: Theories Interventions\& Technologies Lowrence Erlbaun Associates Taylor\& Froncias Group: New York. U.S.A ,p:354.

32- Mary Nugent, Lucy Gannon (2019): Effective Interventions for Struggling Readers. National Educational Psychological Service .Second edition.

33- Mazlina Che Mustafa,\& Siti Hamira Ngajib (2018): Early Childhood Teachers' Challenges in Using English to Interact with Young English 
Language Learners, Human Resource Management Academic Research Society.Vol. 8, No. 6, June 2018, Pg. 60 - 73.

34- Mazur A., \& Jacobsen M. et .al (2015) : Learning Designs Using Filpped Classeoom Instruction, Journal of Learning and Technology (41), (2).

35- Milligan C., (2012) : Full- Day Kindergarten Effectsan later Academic Success, Vol ( 2) ,SAGE Open Journary.

36- Osei, A.M, Liang, \& Stephan, M.A. (2016): The Use of Pre-Reading Activities in Reading Skills Achievement in Preschool Education. European Journal of Educational Research, 5(1), 35-42. doi: 10.12973/eujer.5.1.35

37- Thelal Iqab Owei (2018): Effects of Using a Blended Learning Method on Students' Achievement and Motivation to Learn English in Jordan: A Pilot Case Study.

38-Yee-Fan Gretti (2001) : The effectiveness of the "Whole Language

Approach in Chinese Language Learning among Academically Less-able " A study at a Secondart School in Hong Kong, PH Dissertation Chinese University of Hong Kong ( Peaple s Republic of China).

$$
\text { ثالثا :مراجع شبكة المعلومات ( الانترنت): }
$$

39- اكرم فتحى (10 • ץ) : تطوير نموذج للتصميم التحفيزى للمقرر المطلوب واثره فى نواتج التعلم

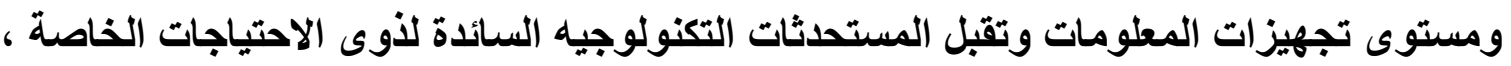

$$
\text { المؤتمر الدولى الرابع للتعلم التكنولوجى و التعلم عن بعد - تعلم مبتكر لمستقبل واعد. }
$$

http://eli.etc.edu.sa/20/5/sites/default/files/220.pdf.

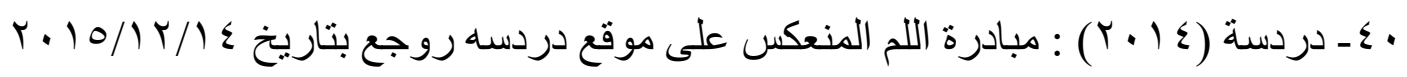

http://www.dardasa.com

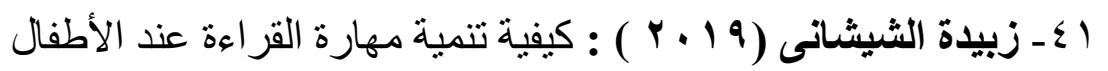


https://mawdoo3.com/\%D9\%83\%D9\%8A\%D9\%81\%D9\%8A\%D8\%A9_\%D8\%A A\%D9\%86\%D9\%85\%D9\%8A\%D8\%A9 \%D9\%85\%D9\%87\%D8\%A7\%D8\%B1 \%D8\%A9 \%D8\%A7\%D9\%84\%D9\%82\%D8\%B1\%D8\%A7\%D8\%A1\%D8\%A9 \%D8\%B9\%D9\%86\%D8\%AF_\%D8\%A7\%D9\%84\%D8\%A3\%D8\%B7\%D9\%81 \%D8\%A7\% D9\%84

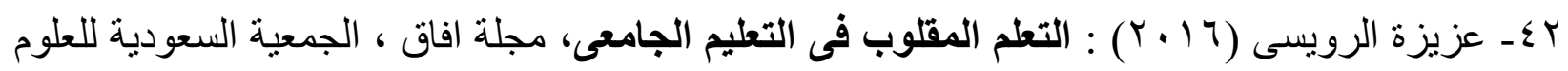
التربوية و النفسية.

http:// gesten.ksu.edu.sa/sites/gesten.ksu.edu.sa/fils/imce-images/49of ag.pdf.

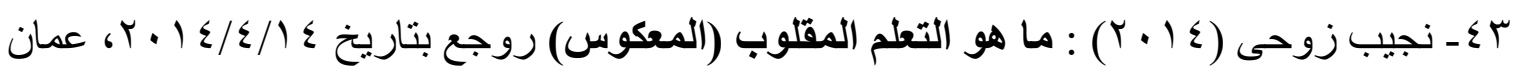
http:// www.new.edu.com/to-classe -inversee.

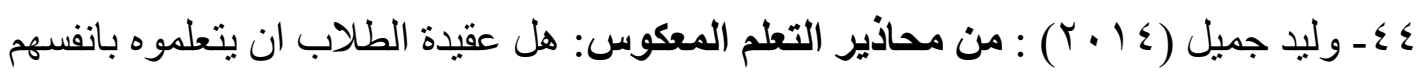
http:// blog.naseef.com/2014/06/05.

45- Brame C., (2013) : Flipping the classroom Vanderbilt University for Teaching. Retrieved 14/04/2016,from http://cft. Vandrbit.edu/guides- sub-pages/flipping- the -classroom.

46- Talfert Robert (2014) : Filipped Learning skepticism: can students really learn on their own?

http:// chronicle.com/blogntwork/catingoutnines/2014/04/3d/filipped- learningskepticison-can-student. 